\title{
Brain Metastases in Oncogene- Addicted Non-Small Cell Lung Cancer Patients: Incidence and Treatment
}

\author{
J. Remon ${ }^{1 *}$ and Benjamin Besse ${ }^{2,3 *}$ \\ ${ }^{1}$ Medical Oncology Department, Hospital Universitari Vall d'Hebron, Barcelona, Spain, ${ }^{2}$ Cancer Medicine Department, \\ Institut Gustave Roussy, Villejuif, France, ${ }^{3}$ University Paris-Sud, Orsay, France
}

Brain metastases (BM) are common in non-small cell lung cancer patients including in molecularly selected populations, such as EGFR-mutant and ALK-rearranged tumors. They are associated with a reduced quality of life, and are commonly the first site of progression for patients receiving tyrosine kinase inhibitors (TKIs). In this review, we summarize incidence of BM and intracranial efficacy with TKI agents according to oncogene

OPEN ACCESS

Edited by:

Marco Lucchi,

Università degli Studi

di Pisa, Italy

Reviewed by:

Minesh P. Mehta,

Baptist Health South Florida,

United States

Emilio Bria,

University of Verona, Italy

*Correspondence:

J. Remon

jremon@vhio.net;

Benjamin Besse

benjamin.besse@gustaveroussy.fr

Specialty section:

This article was submitted to

Thoracic Oncology,

a section of the journal

Frontiers in Oncology

Received: 29 December 2017

Accepted: 14 March 2018

Published: 11 April 2018

Citation:

Remon J and Besse B (2018) Brain Metastases in Oncogene-Addicted Non-Small Cell Lung Cancer Patients: Incidence and Treatment.

Front. Oncol. 8:88.

doi: 10.3389/fonc.2018.00088 driver mutations, focusing on important clinical issues, notably optimal first-line treatment in oncogene-addicted lung tumors with upfront BM (local therapies followed by TKI vs. TKI monotherapy). We also discuss the potential role of newly emerging late-generation TKIs as new standard treatment in oncogene-addicted lung cancer tumors compared with sequential strategies.

Keywords: brain, metastases, non-small cell lung cancer, EGFR, ALK

\section{INTRODUCTION}

Lung cancer is the leading cause of cancer-related deaths worldwide (1). Because of the lack of screening programs in most countries, more than half of non-small cell lung cancer (NSCLC) patients are diagnosed at an advanced stage ${ }^{1}$. The brain is a common metastatic site in this population, with $30 \%$ of patients developing brain metastases (BM) during the course of their disease, with the brain being the only site of metastatic disease in $51 \%$ of these cases. Median delay between diagnosis of the primary tumor and development of BM is 11 months. Up to half of cases, patients present with synchronous diagnosis of BM at the time of diagnosis of the primary lung tumor (2). Ironically, the lifetime incidence of BM is increasing due to prolonged survival seen in NSCLC patients thanks to new systemic therapies and improved neuro-imaging techniques (3). Unfortunately, prognosis associated with BM remains poor with reports of median overall survival (OS) between 3 and 14.8 months (4), and compared to other metastatic sites, BM are responsible for a major decrease in quality of life (5).

The discovery of targetable genomic alterations in approximately $30 \%$ of advanced NSCLC tumors, mainly adenocarcinomas, has altered the therapeutic landscape and outcome of many of these subgroups of NSCLC patients $(6,7)$. In the recent era of personalized treatment targeting these alterations, prognosis of NSCLC patients with BM has improved significantly achieving a median OS of nearly 4 years (8). The question whether BM harbor distinct genetic alterations beyond those observed in primary tumors has not been definitively addressed. Recent data with

${ }^{1}$ Available from: www.seer.cancer.gov (Accessed: March 23, 2018). 
whole-exome sequencing in 86 patient-matched BM (including 38 NSCLC patients) reported 53\% of cases with potentially clinically informative alterations in BM that were not detected in the matched primary-tumor sample (9). However, these findings have a number of technical limitations and are yet to be supported by clinical evidence. On the other hand, response rates (RR) to targeted therapies in molecularly defined NSCLC patients are typically similar in central nervous system (CNS) and extra-CNS disease, arguing for fewer molecular discordances between the primary tumor and CNS metastases, at least for actionable mutations. This is an important issue to resolve for determining the best treatment strategies for managing BM.

One important consideration, when interpreting CNS efficacy with tyrosine kinase inhibitors (TKIs) in molecularly selected NSCLC patients, is the inherent limitation of the standard RECIST criteria for the measurement of baseline CNS disease and response (10). This assessment does not account for potential pseudo-progression correlating with radionecrosis and non-viable tumors in patients who have received brain radiotherapy (11). New imaging tests might offer better characterization of CNS progression vs. pseudo-progression (12). While the systemic efficacy of TKI in oncogene-addicted NSCLC has been well established, their intracranial efficacy is today less well validated for a number of reasons. Brain imaging during followup is often optional in clinical trials, MRI is not commonly used compared to the less sensitive CT scan, and patients with BM are often excluded from NSCLC trials, and when they are accepted, $\mathrm{BM}$ is not a stratification criteria. The CNS is shielded by the blood-brain barrier (BBB) and is considered a "pharmacological sanctuary." The key molecular properties that influence the BBB are the $\mathrm{P}$-glycoprotein (P-gp) or breast cancer resistance protein substrate nature of the TKIs, their molecular weight, polar surface area and lipophilicity index $(\log P)(13)$. These factors may explain why only $2 \%$ of small-molecule drugs are able to effectively cross the BBB (14), likely explaining why the CNS is a frequent site of failure after clinical benefit with some TKIs.

In this review, we summarize the incidence of BM in oncogene-addicted NSCLC patients and CNS efficacy for personalized treatment in these different sub-populations. We also evaluate new challenges such as the value of upfront personalized treatment vs. radiotherapy in oncogene-addicted NSCLC patients with $\mathrm{BM}$ at baseline, and administration of more potent drugs upfront vs. sequential treatment.

\section{EGFR-MUTANT NSCLC PATIENTS}

Within the lung cancer population, activated epidermal growth factor receptor (EGFR) mutations occur in 10\% of Caucasians and $50 \%$ of Asians (15). There are several classes of activating somatic EGFR mutations, with in-frame deletions in exon 19 (ELREA, Del19) and single-point mutations in exon 21 (L858R) being the most common. These mutations predict sensitivity to first- and second-generation EGFR TKIs, such as erlotinib, gefitinib, or afatinib. RRs and progression-free survival (PFS) with EGFR TKIs have proven superior to standard first-line platinum doublet chemotherapy, making them the current upfront standard of care (16). Recently, osimertinib a third-generation EGFR TKI, showed a significant improvement in PFS compared with standard of care (erlotinib or gefitinib) as first-line treatment, making it a new treatment option in the first-line setting (17).

\section{Incidence of BM in EGFR-Mutant NSCLC}

The baseline incidence of BM in EGFR-mutant NSCLC is similar to that of other oncogenic driver mutations, ranging from 23 to $32 \%$ (18-20). The cumulative incidence increases over time $(19,21)$, with a 2-year actuarial risk of CNS progression of approximately 15-20\% when patients received standard of care EGFR TKIs $(21,22)$. BM development on EGFR TKI treatment is significantly more common among patients with baseline BM (2-year cumulative incidence of $47 \%$ among patients with pre-existing BM compared to $11 \%$ among those with no prior BM; $p=0.003$ ) and correlates with a worse outcome $(21,23,24)$. Literature reporting the risk of cumulative incidence of brain progression according to EGFR mutation subtype is contradictory, some studies reporting higher cumulative risk among Del19-mutant tumors (21), and others among L858R-mutant tumors $(22,24)$.

Although, it has been suggested that EGFR mutations appear early during multistep carcinogenesis and may even be associated with an increased propensity for metastatic cell to spread into the brain (25), the lifetime risk is confounded by this molecular subgroup's longer survival. However, some reports suggest that the incidence of BM is higher in EGFR-mutant patients compared to $E G F R$-wild type ( 31.4 vs. $19.7 \%$, odds ratio $1.86,95 \% \mathrm{CI}$ : 1.39-2.49; $p<0.001$ ) (18), but it could be explained by inability of first-generation EGFR TKIs to cross BBB, reported in up to $60 \%$ of patients $(26,27)$. The high incidence and significant rate of CNS failure highlights the need for additional strategies to prevent CNS progression.

\section{Treatment With EGFR TKIs}

First- and second-generation EGFR TKI brain penetration potential, measured by the unbound brain-to-plasma ratio, termed $\mathrm{K}_{p \text {,uu }}$, is very low (28), indicating that penetration into the brain is diffusion-limited or low passive BBB permeability (13). However, the importance of the $\mathrm{BBB}$ for intracranial tumors is debated. Retrospective observational and phase II studies have reported activity with erlotinib and gefitinib in EGFR-mutant patients with BM (29-34). Two studies with erlotinib showed intracranial RRs of 58 and $82 \%$ and intracranial PFS of 10.1 and 11.7 months $(29,30)$. Gefitinib achieved an intracranial RR of $88 \%$ and intracranial PFS of 14.5 months, with a time to salvage brain radiation from diagnosis of 17.9 months (32) (Table 1).

In vivo studies in NSCLC mice showed that afatinib penetrated the $\mathrm{BBB}$ and cerebrospinal fluid (CSF) levels correlated with plasma levels (35). In a compassionate-use program including 31 patients, afatinib demonstrated a 35\% CNS response in molecularly non-selected patients who had previously failed TKI therapy, with a median time to treatment failure of 3.6 months (36). In a combined dataset post hoc analysis in 81 EGFR-mutant NSCLC patients with $\mathrm{BM}$ (30\% had received brain radiotherapy) in the first-line LUX-Lung 3 and LUX-Lung 6 phase III clinical trials, afatinib significantly improved PFS ( 8.2 vs. 5.4 months, hazard ratio (HR) $0.50, p=0.0297$ ) and $\mathrm{RR}(21$ vs. $5 \%, p=0.0027$ ), although without a significant difference in OS (22.4 vs. 
TABLE 1 | Efficacy of EGFR tyrosine kinase inhibitors (TKIs) in EGFR-mutant non-small cell lung cancer (NSCLC) patients and brain metastases (BM)

\begin{tabular}{llrccc}
\hline Drug & Trial & N & $\begin{array}{c}\text { icRR } \\
\text { (\%) }\end{array}$ & $\begin{array}{c}\text { icDoR } \\
\text { (months) }\end{array}$ & $\begin{array}{c}\text { icPFS } \\
\text { (months) }\end{array}$ \\
\hline Erlotinib & Retrospective (29) & 17 & 82 & NA & 11.7 \\
& Ph II (30) & 8 & 58.4 & NA & 10.1 \\
Gefitinib & Ph II (32) & 41 & 88 & NA & 14.5 \\
& Retrospective (34) & 14 & 43 & 7.7 & 9.1 \\
Afatinib & Pooled analysis (37) & 81 & $21^{\text {a }}$ & NA & $8.2^{\text {a }}$ \\
Icotinib & Ph III (38) & 85 & 65 & NA & 10.0 \\
AZD3759 & Ph I (28) & 18 & 83 & NA & NA \\
Osimertinib & AURA + AURA2 & 128 & $54^{\circ}$ & NR & 1 year: $56 \%$ \\
& (49, 50) & & & & 11.7 \\
& AURA3 (51) & 116 & $70^{\mathrm{d}}$ & $8.9^{\mathrm{d}}$ & NR \\
\hline
\end{tabular}

icDOR, intracranial duration of response; icRR, intracranial response rate; icPFS,

intracranial progression-free survival; NA, not available; NR, not reached.

${ }^{a}$ Systemic $R R$ and progression-free survival (PFS).

${ }^{b}$ Patients should have at least 3 metastatic brain lesions.

In 50 evaluable patients.

In 30 evaluable patients with osimertinib.

25.0 months; HR 1.14, $p=0.64$ ) compared with platinum-based chemotherapy (37). The magnitude of the PFS benefit was suggested being increased, for patients who had received prior whole brabin radiotherapy (WBRT, $n=24 ; 13.8$ vs. 4.7 months; HR 0.37 , $p=0.07)$. Evaluation of intracranial response was not assessed as a separate endpoint in these trials (37), however, these results suggest that asymptomatic BM are not a limitation for upfront treatment with an EGFR TKI (Table 1).

Icotinib, another EGFR TKI only available in Asia, gave an intracranial RR of $65 \%$ and median PFS of 10 months in treatmentnaïve EGFR-mutant patients with at least three BM (38). AZD3759 is a novel reversible EGFR TKI, only active against sensitizing EGFR mutations, which was designed to effectively cross the BBB and achieves high drug-free exposure in the brain. In a phase I trial, it achieved an intracranial RR of $83 \%$ among 18 EGFR TKI treatment-naïve patients with evaluable BM (28) (Table 1).

The substitution of threonine to methionine at amino acid position 790 (T790M) in exon 20 of the EGFR gene reduces firstgeneration EGFR TKI binding by enhancing the ATP binding affinity of the kinase domain of the EGFR-mutant receptor (39). It accounts for acquired resistance in approximately $50-60 \%$ of patients $(40,41)$. Knowledge of acquired resistance mechanisms to EGFR TKIs was one of the triggers behind the development of third-generation EGFR-TKIs, such as osimertinib, which are active against exon19 and 21 mutations as well as the T790M mutations. Osimertinib was the first such agent to receive FDA and EMA approval (in November 2015 and February 2016, respectively) for metastatic EGFR-mutant and acquired EGFR T790M-mutant NSCLC patients progressing on or after EGFR TKI therapy ${ }^{2,3}$.

${ }^{2}$ Available from: http://www.fda.gov/MedicalDevices/ProductsandMedicalProcedures/InVitroDiagnostics/ucm301431.htm (Accessed: March 23, 2018).

${ }^{3}$ Available from: http://www.ema.europa.eu/docs/en_GB/document_library/ EPAR___Product_Information/human/004124/WC500202022.pdf (Accessed: March 23, 2018).
The rate of acquired T790M mutations is discordant between intracranial and extracranial metastases. In a study of 78 EGFRmutant patients who had undergone re-biopsy after TKI failure, only $17 \%$ of CNS lesions were T790M mutated compared to $41 \%$ of systemic lesions (42), suggesting that the selection pressure is lower intracranially owing to the lower EGFR TKI concentrations in CSF compared to serum concentrations $(42,43)$. Preclinical data demonstrated greater penetration and brain exposure with osimertinib than with gefitinib, rociletinib, or afatinib (44).

Central nervous system activity of osimertinib was reported in pretreated T790M-positive NSCLC patients in the AURA study phase II extension component (45), the phase II AURA2 trial (46), and was recently confirmed in the phase III AURA3 trial (47) and the first-line FLAURA trial (17). In the pooled analysis of the two phase II trials $(N=411)$, osimertinib demonstrated an overall RR of $66 \%$ and median PFS of 11 months (48). In the pre-specified subgroup analysis of CNS response in this pooled analysis among 128 patients with CNS metastases at baseline, 50 were evaluable for CNS response. CNS response and DCR were 54 and 92\%, respectively, and CNS response was observed regardless of prior radiotherapy. Median CNS duration of response (DOR) was not reached and at 9 months $75 \%$ of patients were estimated to remain in response. Median CNS PFS was not reached (49), with 1-year PFS of 56\% (50). In the AURA3 trial, osimertinib demonstrated significantly greater efficacy in RR (71 vs. $31 \%$ ) and PFS (10.1 vs. 4.4 , HR $0.30,95 \%$ CI: $0.23-0.41$, $p<0.001)$ than platinum-pemetrexed chemotherapy, in 419 T790M-positive NSCLC patients who had progressed on firstline EGFR TKIs (47). Among 116 patients from the AURA3 trial with BM (measurable or not), PFS was longer with osimertinib compared to chemotherapy ( 11.7 vs. 5.6 months, HR $0.32 ; 95 \%$ CI: 0.15-0.69) and cumulative incidence of CNS progression at 6 months was lower with osimertinib compared to chemotherapy (11.5 vs. 28.2\%) (51). Among 46 patients with evaluable BM, the intracranial RR was $70 \%$ with osimertinib compared with $31 \%$ with chemotherapy, with a median DOR of 8.9 vs. 5.7 months, respectively (51) (Table $\mathbf{1}$ ). It has been proposed that BM may not develop secondary resistance mutations to EGFR TKIs that develop during extracranial progression, due to reduced drug penetration of the BBB (52). However, CNS efficacy with osimertinib reported in AURA3 trial, appears to contradict this theory. In the CNS full analysis set $(N=128)$ from FLAURA trial, osimertinib reported improved CNS RR (66 vs. 43\%) and longer CNS PFS (NR vs. 13.9 months, HR 0.48, 95\% CI: 0.26-0.86, $p=0.04$ ) and reduced the risk of CNS progression compared with the standard of care. Among evaluable CNS evaluable patients $(N=41)$, osimertinib improved the CNS RR (91 vs. $68 \%$ ) with similar DOR compared with the standard of care (15.4 vs. 18.7 months) (53).

In light of the reduced CSF concentrations of EGFR TKIs, various studies have examined administration of high doses in an attempt to achieve therapeutic levels (54-57). "Pulsatile" erlotinib at $1,500 \mathrm{mg}$ given weekly resulted in an intracranial RR of $67 \%$ with a median time to CNS progression of 2.7 months in nine patients (55). In a phase I trial, pulse and daily low-dose erlotinib prevented progression of untreated or new CNS metastases, without improving extracranial outcome compared with 
standard-dose (58). However, the limited number of patients, the short follow-up period and the fact that half of the patients with baseline BM had already been treated are confounding factors that prevent any conclusions being reached regarding efficacy in the CNS with this strategy.

\section{Combined EGFR TKIs and Antiangiogenics}

Activity and an acceptable safety profile of bevacizumab, an anti-VEGF monoclonal antibody, have been reported in NSCLC patients with asymptomatic and untreated BM (59). Moreover, in a preclinical model of lung adenocarcinoma, bevacizumab prevented BM formation (60). In a phase II trial in 154 Asian EGFRmutant NSCLC patients, the addition of bevacizumab to erlotinib as first-line treatment significantly improved PFS compared to erlotinib alone (16.0 vs. 9.7 months, HR 0.54 ; $95 \%$ CI: $0.36-0.79$, $p=0.0015)$ (61), leading to EMA approval of the combination in this population in April 2016. Two ongoing phase III trials evaluating erlotinib combined with ramucirumab (NCT02411448) or bevacizumab (BEVERLY study, NCT02633189) compared with erlotinib, will hopefully further validate this strategy.

In the single arm phase II BELIEF trial in 109 Caucasian EGFRmutant NSCLC patients, combined erlotinib and bevacizumab gave median PFS and OS of 13.2 and 28.2 months, respectively. However, the primary endpoint was only met in baseline T790Mpositive tumors with a median PFS of 16 months, whereas in T790M-negative tumors, median PFS was 10.5 months (62). In the subgroup of patients with pretreated BM $(N=21)$, median PFS was 8.8 months. The efficacy of this combination in the BM population does not appear to be superior to standard EGFR TKI therapy (37), however only 21 patients with BM were included in the BELIEF trial. Results from the ongoing randomized phase II BRILLANT trial (NCT0265536), testing bevacizumab plus erlotinib vs. erlotinib in BM EGFR-mutant patients, should reveal the efficacy of this combination in this population. Also the combination of osimertinib and bevacizumab in EGFR-mutant NSCLC patients and BM is currently assessed in a phase II trial (NCT02971501).

\section{ALK-REARRANGED NSCLC PATIENTS}

Anaplastic lymphoma kinase $(A L K)$ rearrangements result from inversions or translocations on chromosome 2 and are present in $~ 5 \%$ of NSCLC tumors, with no apparent differences in incidence according to race. Crizotinib was the first treatment to be approved in this population achieving a median PFS of 10.9 vs. 7.0 months with platinum-pemetrexed chemotherapy in the front-line setting in the phase III PROFILE 1014 study (63). In the subsequent phase III ASCEND-4 trial in ALK-positive (by central immunohistochemistry) NSCLC patients, upfront ceritinib, a second-generation ALK TKI, gave a median PFS of 16.6 vs. 8.8 months with platinum-pemetrexed chemotherapy (64). Based on these results, the FDA approved ceritinib as first-line treatment in ALK-positive NSCLC patients in May 2017. More recently, the phase III ALEX trial demonstrated a significant improvement in PFS with alectinib (a second-generation ALK TKI) compared with crizotinib (25.7 vs. 10.4 months, HR: 0.50, 95\%CI: $0.36-0.70, p<0.001)$ by independent review, and with a better toxicity profile, as first-line treatment in ALK-positive NSCLC patients (65). The EMA and FDA approved alectinib as first-line treatment in 12 October 2017 and in 6 November 2017, respectively. Treatment strategies in this population are provided below and in Figure 1.

\section{Incidence of BM in ALK-Positive NSCLC}

In $A L K$-positive NSCLC patients, CNS metastases affect from 24 to $42 \%$ of patients $(19,65-68)$ with risk increasing over time, reaching 58\% at 3 years (19). In this population, median OS after development of BM was 49.5 months, with no survival differences detected according the number of BM (single vs. more than one BM) (69), confirming the prolonged survival of $A L K$-positive NSCLC patients with BM. However, the CNS is a common site of progression with crizotinib; in patients with known BM (treated or untreated), the CNS was a site of new lesions or non-target progression in $70 \%$ of cases of progression during crizotinib treatment. In patients without BM at the time of crizotinib initiation, $20 \%$ subsequently experienced CNS progression $(68,70)$. It remains controversial whether this increased risk was an expression of the natural $A L K$ rearranged disease course independent of the therapy received, or if, as in EGFR-mutant NSCLC patients, it is related to low CSF penetrance of ALK TKIs. Crizotinib is a substrate for the ATP-binding cassette (ABC) drug efflux transporters, P-gp and $A B C$ subfamily $G$ member 2 , and has been associated with poor accumulation of the drug in the brain, a CSF-to-plasma ratio of 0.0026 reported in a case study (71). In support of this, ABCB1-/- and ABCG2-/- mice had a 25- to 70-fold higher brain concentration following oral administration of crizotinib compared to wild type (71).

Nonetheless clinical evidence for crizotinib CNS efficacy has been reported. A pooled retrospective analysis of crizotinib efficacy in $A L K$-positive NSCLC patients with BM from the PROFILE 1005 phase II and PROFILE 1007 phase III trials has been reported (68). At baseline, $31 \%$ of patients (275 of 888 ) had asymptomatic BM. Analytic subgroups were stratified according to prior brain radiotherapy $(60 \%)$ or not. The intracranial disease control rate (DCR) at 12 weeks was similar in these two groups at 62 and 56\%, respectively. Of note, previously treated patients demonstrated higher CNS objective RR with crizotinib (33 vs. $18 \%$, respectively), as well as prolongation of the median time to intracranial progression (13.2 vs. 7.0 months, respectively; Table 2) (68). Intracranial efficacy of crizotinib in treatmentnaive $A L K$-positive patients was studied in the PROFILE 1014 trial (70). Of 343 patients, 79 (23\%) had treated BM at baseline. Compared to chemotherapy, crizotinib demonstrated longer PFS (9.0 vs. 4.0 months; HR 0.40, 95\% CI: $0.23-0.69, p<0.001$ ) and a better RR ( $77 \%$ vs. $28 \%, p<0.01)$. Crizotinib achieved a 12 -week intracranial DCR of $85 \%$ and median intracranial time to progression of 15.7 months in patients with treated BM (Table 2). CNS progression as the only site of progression on crizotinib was reported in $38 \%$ of patients with treated $\mathrm{BM}$ at baseline and $19 \%$ without (70). In the randomized phase III ALEX trial, crizotinib was used as the standard of care in the control arm and brain MRIs were mandatory at baseline and during follow-up (65). Among the 22 patients with measurable BM 


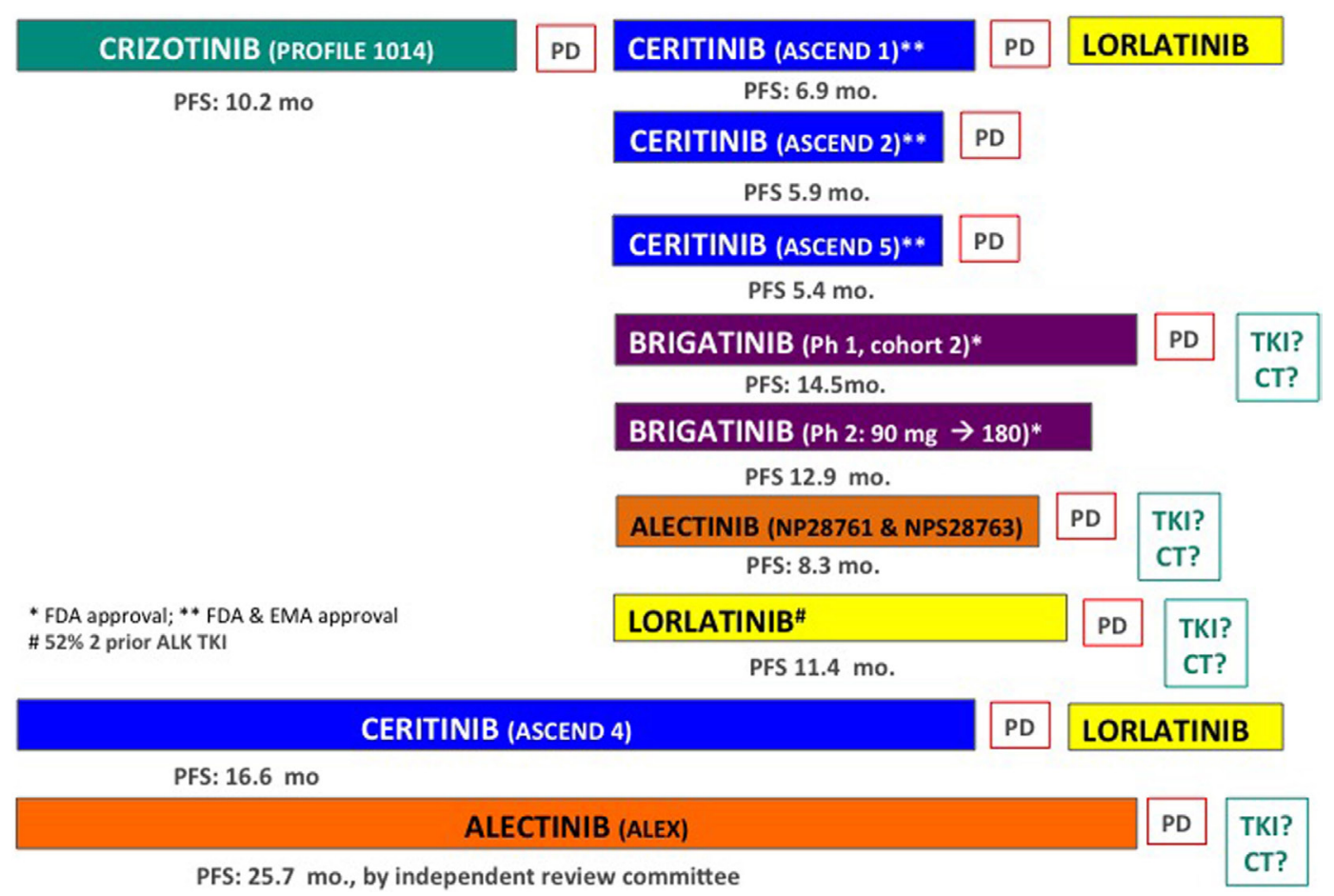

FIGURE 1 | Systematic treatment stratergies in ALK-positive non-small cell lung cancer (NSCLC) patients. TKI, other ALK tyrosine kinase inhibitor; CT, chemotherapy.

at baseline, crizotinib achieved an intracranial RR of $50 \%$ and a median duration of intracranial response of 5.5 months. For the seven patients previously treated with brain radiotherapy, crizotinib gave an intracranial RR of $71 \%$ and median DOR of 17.3 months (72). Despite these data suggesting intracranial efficacy with crizotinib, especially among previously-treated BM patients, recent data showed that the cumulative incidence rate of CNS progression at 12 months was consistently higher with crizotinib compared with alectinib (32 vs. $4.6 \%$ respectively in patients without $\mathrm{BM}$ at baseline; HR 0.14, 95\% CI: 0.06-0.33, $p<0.0001)(65,72)$, suggesting that the risk of BM progression may correlate more closely with ALK TKI subtype and not the natural $A L K$-rearranged disease course.

\section{Treatment With Novel ALK TKIs Ceritinib}

Ceritinib is a second-generation ALK inhibitor that is 20 times as potent as crizotinib. It is effective in $A L K$-positive patients upfront and patients who progress while on crizotinib, including patients with BM (73). In the phase III ASCEND-4 trial, among 121 ALK-positive TKI-naïve NSCLC patients with BM, first-line treatment with ceritinib improved PFS (10.7 vs. 6.7 months, HR 0.70) compared to chemotherapy. Intracranial RR in 22 patients with measurable BM at baseline was $73 \%$, with a median duration of intracranial response of 16.6 months (64). The CNS efficacy of ceritinib in crizotinib-pretreated and ALK-naïve patients was tested in the phase I ASCEND-1 trial (73), as well as the phase II ASCEND-2 (74), and ASCEND-3 (75) trials (Table 2). In the phase III, ASCEND-5 trial in previously treated (chemotherapy and crizotinib) $A L K$-positive NSCLC patients, ceritinib compared with chemotherapy significantly improved PFS across all patient subgroups, including in 133 patients with $\mathrm{BM}$ at baseline (56\% previously treated with brain radiotherapy), from 1.5 months to 4.4 months (HR 0.54, 95\% CI: 0.36-0.80). Among the 17 patients with measurable BM, ceritinib gave a $35 \%$ intracranial RR and median duration of intracranial response of 6.9 months (76). Nonetheless, despite these second-generation more potent ALK TKIs, BM remained the main site of progression among patients with $\mathrm{BM}$ at baseline (76). Based on ceritinib efficacy, an international prospective phase II open-label study is ongoing (ASCEND-7, NCT02336451) specifically evaluating the anti-tumor activity of ceritinib in $A L K$-positive NSCLC patients with $\mathrm{BM}$ or leptomeningeal disease (previously treated with radiotherapy or not).

Gastrointestinal toxicity by ceritinib may reduce treatment compliance. The ASCEND-8 (NCT02299505) aimed to evaluate whether administering ceritinib, 450 or $600 \mathrm{mg}$, with a low-fat meal may enhance gastrointestinal tolerability vs. $750 \mathrm{mg}$ fasted while maintaining similar exposure in 267 treatment-naive ALKpositive NSCLC (neurologically stable BM were stable). The study demonstrated similar efficacy in terms of ORR and DCR with less frequent dose reductions/interruptions and higher relative dose 
TABLE 2 | Efficacy of ALK tyrosine kinase inhibitor (TKIs) in patients with baseline brain metastases (BM).

\begin{tabular}{|c|c|c|c|c|c|c|c|}
\hline Drug & Trial (reference) & Brain M1 & $\begin{array}{c}\text { Measurable } \\
\text { Brain M1 }\end{array}$ & icRR (\%) & $\begin{array}{c}\text { icTTP } \\
\text { (months) }\end{array}$ & $\begin{array}{l}\text { s/ic PFS } \\
\text { (months) }\end{array}$ & $\begin{array}{c}\text { icDOR } \\
\text { (monthss) }\end{array}$ \\
\hline \multirow[t]{2}{*}{ Crizotinib } & PROFILE 1005 + 1007 pooled. ALK-naïve (previous CT) (68) & 275 & $22 / 18^{b}$ & $18 / 33^{b}$ & $7.0 / 13.2$ & NA & $26.4, \mathrm{NR}^{\mathrm{b}}$ \\
\hline & PROFILE 1014. Ph III ALK-naïve (70) & 79 & 79 & $85^{c}$ & 15.7 & sPFS: 9 & NA \\
\hline \multirow[t]{6}{*}{ Ceritinib } & ASCEND 5. Ph III Crizotinib + CT resistant (76) & 133 & 17 & 35 & NA & sPFS: 4.4 & 6.9 \\
\hline & & & & 72.7 & & & 16.6 \\
\hline & ASCEND 4. Ph III ALK-naïve (64) & 121 & 22 & 62 & NA & SPFS: 10.7 & NA \\
\hline & ASCEND 3. Ph II ALK TKI-naïve ${ }^{a}(75)$ & 49 & 13 & 39.4 & NA & sPFS: 10.8 & 9.2 \\
\hline & ASCEND 2. Ph II Crizotinib-resistant (74) & 100 & 33 & 63 & NA & SPFS: 5.4 & 8.2 \\
\hline & ASCEND 1. Ph I Naïve and pretreated (73) & 94 & 36 & $61^{d}$ & NA & NA & $11.1^{\mathrm{d}}$ \\
\hline \multirow[t]{3}{*}{ Alectinib } & Pooled analysis of ph II. Crizotinib resistant (85) & 136 & 50 & 64 & 9.2 & NA & 10.8 \\
\hline & ALUR ph II. Crizotinib and CT resistant $(86,87)$ & 76 & 40 & 54 & NA & sPFS: 9.6 & 17.3 \\
\hline & ALEX. Ph III. ALK TKI-naïve $(65,72)$ & 122 & 21 & 81 & NA & SPFS: 25.7 & \\
\hline \multirow[t]{8}{*}{ Lorlatinib } & Ph I in ALK-positive (11\% crizotinib-naïve) (90) & 41 & 19 & 42 & NA & sPFS: 9.6 & 12.4 \\
\hline & $\mathrm{Ph}$ I in ROS1-positive (90) & 12 & 5 & 60 & NA & SPFS: 7.0 & 12.0 \\
\hline & $\mathrm{Ph} \| \mathrm{in} A L K / R O S 1$-positive (91) & & & & & & \\
\hline & ALK TKI treatment-naïve & 8 & 8 & 75 & NA & NR & NA \\
\hline & Prior crizotinib only and crizotinib $\pm 1-2 \mathrm{CT}$ & 37 & 37 & 68 & NA & NR & NA \\
\hline & No-crizotinib $\mathrm{TKI} \pm \mathrm{CT}$ & 12 & 12 & 42 & NA & SPFS: 5.5 & NA \\
\hline & $2-3 \mathrm{ALK} T K \mathrm{CI} \pm \mathrm{CT}$ & 83 & 83 & 48 & NA & SPFS: 6.9 & NA \\
\hline & ROS1-positive any prior line & 25 & 25 & 56 & NA & sPFS:9.6 & NA \\
\hline \multirow[t]{2}{*}{ Brigatinib } & Ph I ALK-naïve and crizotinib resistant (93) & 46 & 15 & 53 & NA & icPFS: 15.6 & 18.9 \\
\hline & ALTA. Ph II in crizotinib-resistant $(94,95)$ & 153 & 18 & $67^{e}$ & NA & icPFS: $18.4^{\mathrm{e}}$ & $N R^{e}$ \\
\hline
\end{tabular}

icRR, intracranial response rate; icTTP, intracranial time to progression; s/icPFS, systemic/intracranial progression-free survival (PFS); icDOR, intracranial duration of response; CT, chemotherapy; NA, not available; NR, not reached.

${ }^{a} A L K$ TKI naive and chemotherapy-naive or up to three lines of chemotherapy with progression during or after the last chemotherapy regimen.

${ }^{b}$ Data reported for previously untreated BM/previously treated BM.

12 -week intracranial disease control rate.

${ }^{d}$ Results expressed as ALK inhibitor-naive patients, ALK inhibitor-pretreated patients.

ePatients receiving $180 \mathrm{mg} /$ day.

intensity. Ceritinib administered at $450 \mathrm{mg}$ fed dose demonstrated an ORR of $78 \%$ and a median PFS of 17.6 months, suggesting this dose as a potential new treatment regimen. However, fed doses of ceritinib in patients with $\mathrm{BM}$ were not reported to provide a clear recommendation in this subset $(77,78)$.

\section{Alectinib}

Alectinib is a potent ALK TKI, active against several $A L K$ mutations that confer resistance to crizotinib (79). It is able to penetrate the CNS and activity is expected based on animal models showing high brain-to-plasma ratios (0.63-0.94) and activity in intracranial tumor implantation models. Unlike crizotinib and ceritinib, preclinical studies suggest that alectinib is not a substrate of P-gp, a key drug efflux pump typically expressed in the $\mathrm{BBB}$, and that it has greater CNS activity than other ALK TKIs (80). In the clinic, alectinib gave an intracranial RR of 52\% in 21 crizotinib-resistant patients with baseline BM treated in a phase I trial (81). Alectinib was approved by the FDA in 2015 for $A L K$-positive crizotinib-resistant NSCLC patients based on two phase II clinical trials demonstrating a systemic objective RR of $50-52 \%(82,83)$. A pooled analysis evaluating systemic efficacy of alectinib in both phase II trials enrolling 225 ALK-positive crizotinib-resistant NSCLC patients has been performed. Alectinib gave a systemic RR of $51 \%$, and median PFS and OS of 8.3 and 26 months, respectively (84), with $11 \%$ of patients having CNS as the only site of progression (85). Intracranial efficacy of alectinib in this population was assessed in 136 crizotinib-resistant patients with BM (37\% with measurable disease and 70\% previously treated). Intracranial RR in the whole population was $43 \%$ (36\% in previously irradiated vs. $59 \%$ in patients without prior radiation) with a median DOR of 11.1 months. For patients with measurable disease $(N=50)$, the intracranial RR was $64 \%$, with complete response in $22 \%$, and median intracranial DOR was 10.8 months (85). The phase III ALUR trial comparing alectinib with chemotherapy in 107 previously treated (chemotherapy and crizotinib) ALK-positive NSCLC patients, reported improved outcome with alectinib (PFS 9.6 vs. 1.4 months, HR 0.15; 95\% CI: $0.08-0.29 ; p<0.001$ ) (86). Among 76 patients with baseline BM, alectinib achieved an intracranial RR of $36 \%$ reaching to $54 \%$ among the 40 patients with measurable BM (87). These results endorse preclinical data showing promising CNS efficacy profile with alectinib.

In the phase III ALEX trial, 303 previously untreated $A L K$ positive (by immunohistochemistry) NSCLC patients were randomized to receive either alectinib (600 mg twice daily) or crizotinib (250 mg twice daily). Crossover was not allowed. As mentioned previously, PFS was significantly longer with alectinib than with crizotinib and delayed the onset of BM (65). In the ALEX trial, 122 out of 303 (40\%) patients had asymptomatic BM at baseline. Alectinib achieved an intracranial RR of $59 \%$ with a systemic PFS similar to that reported in the whole population (HR 0.40, 95\% CI: $0.25-0.64, p<0.0001$ ) (65), with a median PFS of 14 months among patients with $\mathrm{BM}$ at baseline who had not received previous radiotherapy (72). Among the 21 patients with measurable 
$\mathrm{BM}$, alectinib gave an intracranial RR of $81 \%$ and median DOR of 17.3 months (65) (Table 2). Patients with previously-irradiated BM measurable lesions had higher intracranial RR (86 vs. 79\%) and intracranial DOR (not reached vs. 17.3 months), compared with patients without prior radiotherapy (72). Similarly, the phase III J-ALEX trial in 207 Japanese ALK-positive NSCLC patients demonstrated the superiority of alectinib in terms of PFS over crizotinib (HR 0.34, 95\% CI: 0.17-0.71, $p<0.0001$ ), and delayed risk of CNS progression in patients with $\mathrm{BM}$ at baseline (HR 0.16, 95\% CI: 0.02-1.28) and those without (HR 0.41, 95\% CI: 0.17-1.01). Among 43 patients with BM at baseline, alectinib significantly improved systemic PFS over crizotinib as first-line treatment (HR 0.08; 95\% CI: 0.01-0.61) (88).

\section{Lorlatinib}

Lorlatinib (PF06463922) is a selective, potent, brain-penetrant next-generation ALK and ROS1 TKI, active against most known resistance mutations $(79,89)$. Lorlatinib was tested in a phase I trial in 54 pretreated or treatment-naive $A L K-(N=41)$ or $R O S-1$ $(N=12)$ positive NSCLC patients ( $11 \%$ treatment-naïve, $52 \%$ two or more previous TKIs, and $72 \%$ with BM). Patients reached a $\mathrm{RR}$ of $46 \%$ in the $A L K$-positive population irrespective of the number of prior ALK TKI therapies, and median PFS and DOR of 9.6 and 12.4 months, respectively. Lorlatinib was highly active in the CNS, including intracranial responses in 8 of 19 (42\%) ALKpositive patients with baseline measurable BM, in over a half of whom two or more previous ALK TKIs had failed (90) (Table 2). The recommended dose for the phase II trial was $100 \mathrm{mg} /$ day.

In the phase II trial (91), lorlatinib conferred a clinically meaningful benefit, including substantial intracranial efficacy ranging from 42 to $75 \%$ in patients with advanced $A L K$-positive disease who were treatment-naïve or who had received a range of prior ALK inhibitors and/or chemotherapies (Table 2). In the treatment-naïve cohort $(N=30)$, lorlatinib achieved an RR of 90\%, neither PFS nor DOR were reached, while the intracranial RR was $75 \%$ among eight patients with BM at baseline. Among the 111 heavily pretreated (two or three previous TKI with or without chemotherapy) patients, lorlatinib reached an overall RR of 39\% with median PFS of 6.9 months, and 48\% intracranial response among 48 patients with BM at baseline (91). Lorlatinib received breakthrough therapy designation in April 2017 for ALK-positive patients previously treated with at least one ALK TKI. Based on these results, the ongoing randomized phase III CROWN trial (NCT03052608) is assessing the efficacy of lorlatinib compared to crizotinib as first-line treatment in $A L K$-positive NSCLC patients. Asymptomatic and pretreated BM are not exclusion criteria.

\section{Brigatinib}

Brigatinib is another new ALK TKI (also active against ROS1, EGFR-T790M, IGFR, and FLT3 mutations) with a broader spectrum of preclinical activity than ceritinib and alectinib against known crizotinib-resistant $A L K$-mutants $(79,92)$. Brigatinib was granted break-through therapy designation by the FDA in October 2014 on the basis of its early phase I/II trial data (93). In the phase I trial, among 71 crizotinib-resistant $A L K$-positive NSCLC patients treated with brigatinib the confirmed RR was $62 \%$ with a median PFS of 13.2 months. Among 46 patients with $\mathrm{BM}$ at baseline, the RR was $53 \%$ and $35 \%$ for those with measurable $(n=15)$ and non-measurable $(n=31)$ intracranial metastases, respectively. The median intracranial PFS and DOR in this population was 15.6 and 18.9 months, respectively. The recommended dose for the phase II study was determined to be $180 \mathrm{mg} /$ day with a 7-day lead-in at $90 \mathrm{mg}$ to reduce the risk of pulmonary toxicity (93).

In the phase II trial, 222 crizotinib-refractory $A L K$-positive NSCLC patients were randomized to brigatinib $90 \mathrm{mg} /$ day ( $\mathrm{arm} \mathrm{A}$ ) or $180 \mathrm{mg}$ /day with a 7-day lead-in at $90 \mathrm{mg}$ (arm B) (94), and updated results were recently presented (95). By independent review, the RR was 51 and 55\%, in arms A and B, respectively, and PFS was 9.2 and 16.7 months, respectively, while OS was not reached in arm A and was 27.6 months in arm B. This is the longest PFS in crizotinib-resistant tumors reported with new ALK TKIs. Based on these results, the FDA approved brigatinib in crizotinib-pretreated patients in 28 April 2017. Among the 154 patients with BM at baseline (69\%), intracranial RR (by independent-review) in patients with measurable disease $(N=44)$ was 50 and $67 \%$ in arm $\mathrm{A}$ and $\mathrm{B}$, respectively. For patients with active $\mathrm{BM}(N=34)$ RRs were similar to those with baseline BM, 47 and $73 \%$ in arms A and B, respectively. Median intracranial PFS was 12.8 and 18.4 months in arms A and $\mathrm{B}$, respectively (95). The intracranial efficacy of brigatinib compares favorably with other second-generation ALK TKIs $(74,85)$ (Table 2). Brigatinib is currently being investigated in a randomized phase III ALTA-1L (NCT02737501) trial comparing brigatinib vs. crizotinib in $A L K$-positive TKI-naïve patients. Asymptomatic and pretreated BM are not exclusion criteria. This trial allows crossover from crizotinib to brigatinib and may help to elucidate whether a sequential strategy is better than upfront brigatinib.

\section{Ensartinib}

Efficacy of ensartinib (X-396) $225 \mathrm{mg} /$ day in an expansion study has been reported. Forty of the 80 enrolled patients were evaluable for response, achieving 58\% partial responses (88\% in eight crizotinib-naïve patients, and $64 \%$ in 22 crizotinib-resistant) (96). Updated results among 15 TKI-naïve patients showed an $80 \%$ RR and median PFS of 23.8 months (97). CNS responses [(60\% partial responses) were observed in both crizotinib-naïve and crizotinib-resistant populations, with a median DOR of 5.8 months (98)]. The ongoing phase III XALT3 (NCT02767804) will compare ensartinib with crizotinib as first-line treatment (previous chemotherapy allowed).

\section{OTHER MOLECULAR ALTERATIONS: ROS1, RET, BRAF, AND NTRK}

\section{ROS1 Rearrangements}

ROS1 rearrangement occurs in approximately 1 to $2 \%$ of NSCLC patients. Compared with ALK rearrangements, ROS1 rearrangements are associated with lower rates of extrathoracic metastases, including fewer BM at initial metastatic diagnosis (19 vs. $39 \%$, $p=0.033$ ) (99), however ROS1 does increase the likelihood of BM (100).

In 50 ROS1-positive NSCLC patients, crizotinib achieved an RR of $72 \%$ and median PFS of 19.2 months (101). Based on these 
results, the FDA and EMA approved crizotinib for treatment of ROS1-positive NSCLC patients in March and August 2016, respectively. Recently, a phase II trial in 32 Asian ROS1-positive NSCLC patients, ceritinib gave an RR of $62 \%$, median PFS of 9.3 months (19.3 months among 30 crizotinib-naïve patients), and median OS of 24 months. Among eight patients with BM, intracranial RR with ceritinib was $63 \%$ (102). In a phase I trial with lorlatinib, 12 ROS1-positive NSCLC patients achieved an intracranial RR of $50 \%$ ( $80 \%$ among five patients with target lesions) and median systemic PFS and DOR of 7 and 12 months, respectively (90) (Table 2 ).

In a phase II study in 47 ROS-positive NSCLC patients $(28 \%$ TKI-naïve, $64 \%$ one previous TKI and $8 \%$ two or more previous TKIs) treated with lorlatinib, the RR was $36 \%$, with a $45 \%$ DCR at 24 weeks, and median PFS and DOR of 9.6 and 13.8 months, respectively (91). Among the 25 patients with $\mathrm{BM}$ at baseline, intracranial RR was 56\%.

Entrectinib is another ROS1 TKI (also active against $A L K$ and $N T R K)$ specifically designed to cross the BBB. In a phase I/II trial, entrectinib (600 mg QD) achieved a RR of 78\% and median PFS of 29.6 months among 32 treatment-naïve ROS1-positive NSCLC patients. The intracranial RR was $83 \%$ among 11 patients with $B M$ at baseline $(103,104)$. Pending questions are the best treatment sequential strategy and whether ROS1-positive NSCLC patients with BM should be treated upfront with entrectinib. Given the low ROS-1 incidence, it is difficult to perform a randomized trial comparing different treatment strategies.

\section{RET Rearrangements}

In NSCLC, RET rearrangements occur in 1 to $2 \%$ of unselected cases and $16 \%$ of NSCLC tumors that lack other oncogenic drivers. They are more common in adenocarcinomas and in never or lighter-smokers $(105,106)$. RET-rearranged NSCLC patients benefit from pemetrexed-based chemotherapy to a comparable extent as $A L K$ - and ROS1-rearranged patients (107). Multikinase inhibitors, such as cabozantinib (108) and vandetanib $(109,110)$ in phase II or retrospective studies (105), have limited efficacy, with RR between 18 and 53\%, median PFS between 2.3 and 4.5 months $(105,108-110)$, and median OS of 6.8 months (105). It has been speculated that the type of fusion partner may play a role in determining treatment response (109); however, this was not validated in the retrospective study (105).

Baseline BM incidence in RET-rearranged NSCLC is $27 \%$, without differences in age, smoking status or fusion-partner type. Lifetime incidence of BM in RET-rearranged NSCLC patients is $49 \%$. In 37 patients treated with multikinase inhibitors with activity against RET, there were no significant differences in median PFS (2.1 vs. $2.1, p=041$ ) or median OS (3.9 vs. 7.0 months, $p=0.10)$ in patients with $\mathrm{BM}(N=10)$ vs. without $(N=27)(111)$. In the phase II trial with cabozantinib, baseline untreated BM were present in five patients. Cabozantinib achieved intracranial disease control in two patients with measurable disease $(-34$ and $-1 \%)$. Brain progression during TKI treatment may be less common than in other oncogenic alterations. Of 22 patients who discontinued cabozantinib, BM was the cause in only $10 \%$ of cases (111). Similarly, intracranial responses have been reported with alectinib, one patient responding after escalating alectinib to $900 \mathrm{mg}$ twice daily (112). The efficacy of alectinib (900-1200 mg/day) as first-line treatment in RET-positive NSCLC patients will be assessed in a multi-cohort phase II/III B-FAST trial (NCT03178552). Treated and asymptomatic BM will be allowed. LOXO-292, another RET TKI has reported tolerability and efficacy in RET-dependent cancers even in progressive BM after alectinib (113).

In a phase I trial, vandetanib and everolimus showed antitumor activity in RET-positive NSCLC patients with BM (114, 115). The short-term outcomes with multikinase inhibitors with activity against RET compared to EGFR/ALK TKIs in EGFRmutant/ALK-rearranged NSCLC, strongly suggest that there is a need for more selective and potent RET targeted agents as monotherapy or in combination in order to enhance activity (116).

\section{BRAF-Mutants}

The combination of the BRAF inhibitor dabrafenib with the MEK inhibitor trametinib was approved by the FDA and EMA based on clinical activity in 57 pretreated BRAF-V600E-mutated NSCLC patients (1-2\% of lung adenocarcinoma patients) following a phase II trial giving an RR of $67 \%$ and median PFS and OS of 8.6 and 18.2 months, respectively, however no data regarding CNS efficacy are available (117). Similar outcomes were recently replicated among 36 TKI-naïve BRAF (V600E)-mutant NSCLC patients (118). In melanoma BM patients, this combination has reported intracranial responses (119), making it highly probable that activity will be observed in NSCLC patients, although this needs to be validated.

\section{NTRK Rearrangements}

Fusions involving the genes NTRK1, NTRK2, and NTRK3 are oncogenic drivers. They encode the proteins TRKA, TRKB, and TRKC, respectively, and play roles in neuronal development, cell survival, and cellular proliferation (104). These fusion genes have been detected in a variety of tumors including lung in up to $3 \%$ of cases, using different assay (NGS or FISH-based) (120). Entrectinib has reported efficacy in NTRK-positive tumors, including NSCLC patients, with a median PFS of 15.6 months (104) and also intracranial activity $(104,120)$, confirming that entrectinib crosses the BBB. Larotrectinib (LOXO 101) is a panTRK TKI. In a phase I clinical trial with 55 NTRK-positive solid tumors (five NSCLC patients), larotrectinib achieved an RR of $78 \%$ across a wide range of ages and tumor types (121). CNS efficacy of this agent remains unknown.

\section{UPFRONT TKIs vs. UPFRONT RADIOTHERAPY IN ONCOGENE- ADDICTED NSCLC}

In oncogene-addicted NSCLC, TKIs have clearly demonstrated increased CNS efficacy, including with next-generation TKIs, which are more potent than first-generation TKIs. Most data have been generated in EGFR- or $A L K$-positive patients, although similar outcomes are expected with other druggable alterations. Nonetheless, alternative treatment options exist in this group such 
as surgery, WBRT or stereotactic radiosurgery (SRS) (122), and the optimal treatment combination or sequence remains unclear.

\section{Sequential Strategies}

A systematic review and meta-analysis of 12 non-comparative studies in 363 EGFR-mutant NSCLC patients with BM, showed evidence that upfront radiotherapy (SRS or WBRT) improved survival outcomes (123). However, this study is based on published data and not on individual patient data limiting its validation. This study also reported that radiotherapy caused more neurological adverse events relative to EGFR TKIs alone. In a retrospective multi-institutional analysis in 351 EGFR-mutant TKI-naïve NSCLC patients with BM, median OS for three alternative strategies, SRS followed by an EGFR TKI ( $n=100)$, WBRT followed by an EGFR TKI $(n=120)$, or an upfront EGFR TKI $(n=131)$, was 46,30 , and 25 months, respectively $(p<0.001)$ (124). In a multivariate analysis, SRS and WBRT vs. EGFR TKI were associated with improved OS, but not with median time to intracranial progression, suggesting that an upfront EGFR TKI and deferred radiotherapy is associated with inferior OS. SRS followed by EGFR-TKI resulted in the longest OS and allowed patients to avoid the potential neurocognitive sequelae of WBRT. However, the retrospective setting meant that data for quality of life and chronic neurocognitive assessments, extracranial disease burden were unavailable, and randomized study design was not used, all of which can be considered as limitations of this analysis. In addition, it is likely that there were a higher number of oligo-metastatic patients in the SRS arm, in whom there is not an urgent need for a TKI to control the extracranial disease, which would generate a major bias.

In a retrospective study $(n=97)$, intracranial PFS was improved in patients who received upfront radiotherapy followed by icotinib compared to those receiving icotinib alone, although without OS improvement (125). However, the absence of randomization makes it difficult to draw a conclusion. On the other hand, in a phase III trial, upfront icotinib $(N=85)$ compared with WBRT (30 Gy) plus chemotherapy $(N=91)$ in EGFR-mutant patients with at least three $\mathrm{BM}$ significantly improved intracranial PFS (10.0 vs. 4.8 months; HR $0.56,95 \%$ CI: $0.36-0.90 ; p=0.014$ ), intracranial RR ( 67.1 vs. $40.9 \%, p<0.001)$, and systemic RR ( 55.0 vs. $11.1 \%, p<0.001$ ), with a better toxicity profile. Median OS had no significant difference between the arms (18.0 vs. 20.5 months; HR $0.93,95 \%$ CI: $0.60-1.44, p=0.734)(38)$.

Any of these studies evaluated radiotherapy strategies compared to third-generation EGFR TKIs, so, a prospective randomized trial evaluating intracranial progression after SRS (to avoid the potential neurocognitive sequelae of WBRT) followed by third-generation EGFR TKI vs. third-generation EGFR TKI followed by SRS is needed. The clinical question has also been raised as to whether SRS as consolidative treatment in brain residual disease after EGFR TKI response could improve intracranial PFS in this population or whether this radiotherapy should be only administered in cases of progression on an EGFR TKI.

\section{Concomitant Strategies}

In a recent meta-analysis, radiotherapy plus EGFR TKIs resulted in a superior RR and DCR, and markedly prolonged the CNStime to progression and OS of NSCLC patients with BM (126), although patients were not selected according to EGFR status. The role of combining an EGFR TKI with WBRT was investigated in a single arm phase II trial of 40 patients (17 EGFR-mutant) (127). Patients received erlotinib $150 \mathrm{mg} /$ day for 1 week, followed by erlotinib with concurrent WBRT ( $2.5 \mathrm{~Gy} /$ day, 5 days per week, to $35 \mathrm{~Gy}$ ) and underwent formal cognitive testing before enrollment and at each follow-up visit. In the EGFR-mutant subset, patients had longer OS compared to wild-type EGFR (19.1 vs. 9.3 months, respectively). Erlotinib was well tolerated in combination with WBRT with no unexpected cases of neurotoxicity.

In a retrospective study in 133 EGFR-mutant patients with BM, radiotherapy (WBRT, SRS) and EGFR TKIs (erlotinib, gefitinib) improved median cranial PFS (16.0 vs. 11.5 moths, $p=0.017)$ and median OS (22 vs. 15 months, $p=0.015)$ compared with EGFR TKIs alone (128). On the contrary, in another retrospective cohort of 230 EGFR-mutant BM NSCLC patients, the addition of WBRT to EGFR TKIs compared to EGFR TKIs alone did not result in significant differences in intracranial PFS (7.4 vs. $6.9, p=0.23$ ) or systemic PFS (7.9 vs. $7.5, p=0.55$ ), and combined treatment was associated with worse survival (26.4 vs. 21.6 months, $p=0.049$ ) (129). These results should be interpreted with caution given the sample sizes, absence of evaluation of side effects and non-randomized study design. While it can be argued that EGFR TKIs can be safely administered with concurrent WBRT (although for $A L K$-positive patients no data are available), high level evidence to support this is lacking, and concomitant strategies are not overtly recommended in either clinical guidelines (122) or in a recent systematic review (130). In cases of asymptomatic BM patients, given the unclear potential synergistic cognitive toxicities caused by combined therapies, WBRT or SRS should be delayed when other effective systemic therapies are available. A recent systematic literature review about results of combined irradiation and targeted therapies has been also recently published (131).

\section{Continuing TKIs With and Without Local Therapy}

Many strategies to treat CNS disease in ALK-positive NSCLC patients have been reported as case reports, such as high-dose crizotinib with a limited intracranial PFS of 1 month (132) and high-dose pemetrexed in combination with high-dose crizotinib with overall stable cerebral disease for 7 months. However, it remains unknown whether the response is attributable to one or both drugs given at high dose (133). In preclinical models, for enhancing CNS drug penetration, P-gp inhibitors such as elacridar, increased the intracranial concentration of crizotinib $\sim 70$-fold (134).

In $120 A L K$-positive NSCLC patients continuing crizotinib beyond initial progression (51\% with brain progression), longer median survival was reported compared with patients who received other chemotherapy (16.4 vs. 5.4 months) (135), although this benefit could also be related to local therapies and more indolent disease in the crizotinib arm. Treating isolated CNS progression with local therapies (surgery and/or radiotherapy) while continuing crizotinib could be viewed as an acceptable option (136). In the PROFILE 1014 study, among 25 
patients with intracranial progression on crizotinib, 19 received radiotherapy, while continued crizotinib achieved a median treatment time beyond progression of 5.1 months, which was longer than the 2.9 months achieved with crizotinib beyond progression among patients with extracranial progression (70). In a retrospective single-institution study, local therapy (either surgery or radiotherapy) for BM in EGFR-mutant (17 treated with erlotinib) or ALK-rearranged (38 treated with crizotinib) NSCLC patients and CNS progression allowed continuation of therapy for an additional 7.1 months (137).

Recent studies have reported that $A L K$-positive NSCLC patients with BM treated with SRS and/or WBRT and TKIs have prolonged survival $(68,69,138)$. Given the extended OS for $A L K$-positive patients and frequent need for repeated courses of CNS radiotherapy, SRS is the preferred strategy for minimizing cerebral toxicity. Synergistic efficacy of crizotinib and radiotherapy could be explained by increased BBB permeability and decreased P-gp expression following irradiation (139). These results suggest intracranial interventions and TKIs beyond progression are of value in patients with asymptomatic and limited CNS progression on a TKI. This SRS strategy is being validated in an ongoing phase II clinical trial (NCT02314364) among oncogene-addicted (EGFR-, $A L K$-, ROS1-positive) NSCLC patients with up to four BM.

The promising CNS activity of the next-generation TKIs suggests that switching targeted agents may be a reasonable alternative to local therapies. However, prospective data are needed to determine which strategy offers the best OS, intracranial control rate, quality of life and therapeutic ratio, taking into account the number of $\mathrm{BM}$ and whether patients are symptomatic at the time of progression.

\section{Second- or Third-Generation TKIs Upfront or Sequentially}

In EGFR-mutant NSCLC patients, osimertinib has reported higher intracranial activity compared with chemotherapy (51) and first-generation EGFR TKIs (17), and longer delay of onset of BM (51). However, lack of stratification according the presence of BM, no reported survival benefit with osimertinib and no prospective validation of this efficacy, limit interpretation. Nonetheless, preclinical data strongly support the increased intracranial efficacy of osimertinib compared with other EGFR TKIs (44). The ongoing phase II APPLE trial (NCT02856893) assesses the optimal strategy for delivering osimertinib in EGFRmutant NSCLC patients and will prospectively validate the efficacy of osimertinib among those patients with BM at baseline (stratification criteria and brain MRI will be performed at baseline) and also the time to radiological brain progression respect to with first-generation EGFR TKI (gefitinib) (140).

In $A L K$-positive NSCLC patients, based on this significant PFS improvement with alectinib and the delay of CNS progression compared with the current standard first-line crizotinib in $A L K$-positive NSCLC patients, alectinib has became a new standard treatment, and is approved by the EMA and FDA. However, it has not yet been demonstrated whether upfront treatment with second-generation ALK TKIs impact OS compared with sequential treatment strategies (Figure 1). In ALK-positive NSCLC patients, 4-year OS was $57 \%$ with upfront crizotinib in the randomized phase III PROFILE 1014 trial $(N=172)$, and was $70 \%$ with alectinib (300 mg twice daily) among 43 Japanese patients included in a phase II trial (141). Although data are immature, no survival benefit has been reported with upfront alectinib compared with crizotinib in the ALEX trial (65). Also, in PROFILE 1014, patients who received crizotinib followed by another ALK-TKI had longer OS compared with those randomized to chemotherapy followed by no ALK-TKI or other treatment (who had the poorest OS), suggesting a potential benefit of sequential strategies (142).

In a multicentre retrospective study, OS in patients treated with crizotinib followed by alectinib tended to be longer than in patients treated with alectinib alone (143) and median OS up to 50 months has been reported in patients who receive sequential strategies with upfront crizotinib $(144,145)$. A French nationwide retrospective cohort (CLINALK study) with 318 ALKpositive NSCLC patients reported that patients who received next-generation ALK TKIs after crizotinib progression (ceritinib, alectinib, lorlatinib; $N=84$ ) had improved OS, reaching a median of 89.6 months (146). Large-scale prospective studies are needed to confirm these preliminary observations.

Finally, each ALK TKI is associated with a distinct spectrum of $A L K$-resistant mutations, and the frequency of mutations increases significantly after treatment with second-generation ALK TKIs (20\% with crizotinib vs. 53\% with alectinib) (79). It is important to note that there are few new ALK TKIs that may overcome alectinib resistance, and efficacy is dependent on the acquired $A L K$ mutation subtype upon progression on alectinib (79). Lack of a tissue biopsy for molecular profiling at progression and limited access to new ALK TKIs worldwide might limit access to subsequent therapies in alectinib-resistant diseases. Validation of liquid biopsies for dynamic markers of TKI efficacy (147) as well as predictive markers for personalized treatment at progression on ALK TKIs is also a challenge. On the other hand, the high CNS response and the delay in the onset of BM with alectinib, which could have a positive impact on patients' quality of life, might justify first-line treatment with alectinib in this population.

\section{CONCLUSION}

Brain metastases are common in NSCLC including in molecularly selected populations, and are associated with a reduced quality of life. A multidisciplinary approach is the optimal strategy in oncogene-addicted NSCLC patients with BM. Based on the available clinical data and long OS in patients with asymptomatic synchronous BM at diagnosis, upfront treatment with TKIs alone should be considered with close CNS surveillance for early intervention in patients with an inadequate CNS response. This strategy may defer CNS radiotherapy and avoid long-term neurologic sequelae associated with local therapies. For patients with symptomatic BM, initial TKI therapy is an option, especially in EGFR-mutant and ALK-positive NSCLC patients treated with new EGFR and ALK TKIs based on their higher CNS efficacy. In other cases, sequential treatment initiated with local therapy followed by a TKI is appropriate. For patients who experience CNS progression with controlled extracranial disease while on TKI treatment, local therapy 
(preferably SRS) followed by the same TKI is an option in patients with a limited number of lesions or who are asymptomatic. In cases of multiple CNS progression, a switch to another TKI with higher CNS-penetration activity with or without WBRT is appropriate.

\section{REFERENCES}

1. Ferlay J, Soerjomataram I, Dikshit R, Eser S, Mathers C, Rebelo M, et al. Cancer incidence and mortality worldwide: sources, methods and major patterns in GLOBOCAN 2012. Int J Cancer (2015) 136:E359-86. doi:10.1002/ ijc. 29210

2. Berghoff AS, Schur S, Füreder LM, Gatterbauer B, Dieckmann K, Widhalm G, et al. Descriptive statistical analysis of a real life cohort of 2419 patients with brain metastases of solid cancers. ESMO Open (2016) 1:e000024. doi:10.1136/ esmoopen-2015-000024

3. Eichler AF, Chung E, Kodack DP, Loeffler JS, Fukumura D, Jain RK. The biology of brain metastases-translation to new therapies. Nat Rev Clin Oncol (2011) 8:344-56. doi:10.1038/nrclinonc.2011.58

4. Sperduto PW, Kased N, Roberge D, Xu Z, Shanley R, Luo X, et al. Summary report on the graded prognostic assessment: an accurate and facile diagnosisspecific tool to estimate survival for patients with brain metastases. J Clin Oncol (2012) 30:419-25. doi:10.1200/JCO.2011.38.0527

5. Peters S, Bexelius C, Munk V, Leighl N. The impact of brain metastasis on quality of life, resource utilization and survival in patients with nonsmall-cell lung cancer. Cancer Treat Rev (2016) 45:139-62. doi:10.1016/j. ctrv.2016.03.009

6. Barlesi F, Mazieres J, Merlio J-P, Debieuvre D, Mosser J, Lena H, et al. Routine molecular profiling of patients with advanced non-small-cell lung cancer: results of a 1-year nationwide programme of the French cooperative thoracic intergroup (IFCT). Lancet (2016) 387:1415-26. doi:10.1016/ S0140-6736(16)00004-0

7. Kris MG, Johnson BE, Berry LD, Kwiatkowski DJ, Iafrate AJ, Wistuba II, et al. Using multiplexed assays of oncogenic drivers in lung cancers to select targeted drugs. JAMA (2014) 311:1998-2006. doi:10.1001/jama.2014.3741

8. Sperduto PW, Yang TJ, Beal K, Pan H, Brown PD, Bangdiwala A, et al. Estimating survival in patients with lung cancer and brain metastases: an update of the graded prognostic assessment for lung cancer using molecular markers (lung-molGPA). JAMA Oncol (2017) 3(6):827-31. doi:10.1001/ jamaoncol.2016.3834

9. Brastianos PK, Carter SL, Santagata S, Cahill DP, Taylor-Weiner A, Jones RT, et al. Genomic characterization of brain metastases reveals branched evolution and potential therapeutic targets. Cancer Discov (2015) 5:1164-77. doi:10.1158/2159-8290.CD-15-0369

10. Gandhi L, Ignatius Ou S-H, Shaw AT, Barlesi F, Dingemans A-MC, Kim D-W, et al. Efficacy of alectinib in central nervous system metastases in crizotinibresistant ALK-positive non-small-cell lung cancer: comparison of RECIST 1.1 and RANO-HGG criteria. Eur J Cancer (1990) 2017(82):27-33. doi:10.1016/ j.ejca.2017.05.019

11. Ou S-HI, Klempner SJ, Azada MC, Rausei-Mills V, Duma C. Radiation necrosis presenting as pseudoprogression (PsP) during alectinib treatment of previously radiated brain metastases in ALK-positive NSCLC: implications for disease assessment and management. Lung Cancer (2015) 88:355-9. doi:10.1016/j.lungcan.2015.03.022

12. Chuang M-T, Liu Y-S, Tsai Y-S, Chen Y-C, Wang C-K. Differentiating radiation-induced necrosis from recurrent brain tumor using MR perfusion and spectroscopy: a meta-analysis. PLoS One (2016) 11:e0141438. doi:10.1371/ journal.pone. 0141438

13. Di L, Rong H, Feng B. Demystifying brain penetration in central nervous system drug discovery. Miniperspective. J Med Chem (2013) 56:2-12. doi:10.1021/jm301297f

14. Pardridge WM. The blood-brain barrier: bottleneck in brain drug development. NeuroRx (2005) 2:3-14. doi:10.1602/neurorx.2.1.3

15. Midha A, Dearden S, McCormack R. EGFR mutation incidence in nonsmall-cell lung cancer of adenocarcinoma histology: a systematic review and global map by ethnicity (mutMapII). Am J Cancer Res (2015) 5(9): 2892-911.

\section{AUTHOR CONTRIBUTIONS}

Review concept, design, acquisition, analysis, and interpretation of data performed equally by BB and JR.

16. Reguart N, Remon J. Common EGFR-mutated subgroups (Del19/L858R) in advanced non-small-cell lung cancer: chasing better outcomes with tyrosine-kinase inhibitors. Future Oncol (2015) 11(8):1245-57. doi:10.2217/ fon. 15.15

17. Soria J-C, Ohe Y, Vansteenkiste J, Reungwetwattana T, Chewaskulyong B, Lee $\mathrm{KH}$, et al. Osimertinib in untreated EGFR-mutated advanced nonsmall-cell lung cancer. N Engl J Med (2018) 378(2):113-25. doi:10.1056/ NEJMoa1713137

18. Iuchi T, Shingyoji M, Itakura M, Yokoi S, Moriya $Y$, Tamura H, et al. Frequency of brain metastases in non-small-cell lung cancer, and their association with epidermal growth factor receptor mutations. Int J Clin Oncol (2015) 20:674-9. doi:10.1007/s10147-014-0760-9

19. Rangachari D, Yamaguchi N, VanderLaan PA, Folch E, Mahadevan A, Floyd SR, et al. Brain metastases in patients with EGFR-mutated or ALK-rearranged non-small-cell lung cancers. Lung Cancer (2015) 88:108-11. doi:10.1016/j. lungcan.2015.01.020

20. Hendriks LEL, Smit EF, Vosse BA, Mellema WW, Heideman DA, Bootsma GP, et al. EGFR mutated non-small cell lung cancer patients: more prone to development of bone and brain metastases? Lung Cancer (2014) 84:86-91. doi:10.1016/j.lungcan.2014.01.006

21. Heon S, Yeap BY, Britt GJ, Costa DB, Rabin MS, Jackman DM, et al. Development of central nervous system metastases in patients with advanced non-small cell lung cancer and somatic EGFR mutations treated with gefitinib or erlotinib. Clin Cancer Res (2010) 16:5873-82. doi:10.1158/10780432.CCR-10-1588

22. Patel SH, Rimner A, Foster A, Zhang Z, Woo KM, Yu HA, et al. Patterns of initial and intracranial failure in metastatic EGFR-mutant non-small cell lung cancer treated with erlotinib. Lung Cancer (2017) 108:109-14. doi:10.1016/j. lungcan.2017.03.010

23. Heon S, Yeap BY, Lindeman NI, Joshi VA, Butaney M, Britt GJ, et al. The impact of initial gefitinib or erlotinib versus chemotherapy on central nervous system progression in advanced non-small cell lung cancer with EGFR mutations. Clin Cancer Res (2012) 18:4406-14. doi:10.1158/1078-0432. CCR-12-0357

24. Ma X, Zhu H, Guo H, Han A, Wang H, Jing W, et al. Risk factors of brain metastasis during the course of EGFR-TKIs therapy for patients with EGFRmutated advanced lung adenocarcinoma. Oncotarget (2016) 7:81906-17 doi:10.18632/oncotarget.11918

25. Matsumoto S, Takahashi K, Iwakawa R, Matsuno Y, Nakanishi Y, Kohno T, et al. Frequent EGFR mutations in brain metastases of lung adenocarcinoma. Int J Cancer (2006) 119:1491-4. doi:10.1002/ijc.21940

26. Omuro AMP, Kris MG, Miller VA, Franceschi E, Shah N, Milton DT, et al. High incidence of disease recurrence in the brain and leptomeninges in patients with nonsmall cell lung carcinoma after response to gefitinib. Cancer (2005) 103:2344-8. doi:10.1002/cncr.21033

27. Lee YJ, Choi HJ, Kim SK, Chang J, Moon JW, Park IK, et al. Frequent central nervous system failure after clinical benefit with epidermal growth factor receptor tyrosine kinase inhibitors in Korean patients with nonsmall-cell lung cancer. Cancer (2010) 116:1336-43. doi:10.1002/ cncr. 24877

28. Ahn M-J, Kim D-W, Cho BC, Kim S-W, Lee JS, Ahn J-S, et al. Activity and safety of AZD3759 in EGFR-mutant non-small-cell lung cancer with CNS metastases (BLOOM): a phase 1, open-label, dose-escalation and dose-expansion study. Lancet Respir Med (2017) 5(11):891-902. doi:10.1016/ S2213-2600(17)30378-8

29. Porta R, Sánchez-Torres JM, Paz-Ares L, Massutí B, Reguart N, Mayo C, et al. Brain metastases from lung cancer responding to erlotinib: the importance of EGFR mutation. Eur Respir J (2011) 37:624-31. doi:10.1183/ 09031936.00195609

30. Wu Y-L, Zhou C, Cheng Y, Lu S, Chen G-Y, Huang C, et al. Erlotinib as second-line treatment in patients with advanced non-small-cell lung cancer 
and asymptomatic brain metastases: a phase II study (CTONG-0803). Ann Oncol (2013) 24:993-9. doi:10.1093/annonc/mds529

31. Park SJ, Kim HT, Lee DH, Kim KP, Kim S-W, Suh C, et al. Efficacy of epidermal growth factor receptor tyrosine kinase inhibitors for brain metastasis in non-small cell lung cancer patients harboring either exon 19 or 21 mutation. Lung Cancer (2012) 77:556-60. doi:10.1016/j.lungcan.2012.05.092

32. Iuchi T, Shingyoji M, Sakaida T, Hatano K, Nagano O, Itakura M, et al. Phase II trial of gefitinib alone without radiation therapy for Japanese patients with brain metastases from EGFR-mutant lung adenocarcinoma. Lung Cancer (2013) 82:282-7. doi:10.1016/j.lungcan.2013.08.016

33. Zhang Q, Zhang X, Yan H, Jiang B, Xu C, Yang J, et al. Effects of epidermal growth factor receptor-tyrosine kinase inhibitors alone on EGFR-mutant non-small cell lung cancer with brain metastasis. Thorac Cancer (2016) 7:648-54. doi:10.1111/1759-7714.12379

34. Hotta K, Kiura K, Ueoka H, Tabata M, Fujiwara K, Kozuki T, et al. Effect of gefitinib ('Iressa', ZD1839) on brain metastases in patients with advanced non-small-cell lung cancer. Lung Cancer (2004) 46:255-61. doi:10.1016/j. lungcan.2004.04.036

35. Zhang S-R, Zhu L-C, Jiang Y-P, Zhang J, Xu R-J, Xu Y-S, et al. Efficacy of afatinib, an irreversible ErbB family blocker, in the treatment of intracerebral metastases of non-small cell lung cancer in mice. Acta Pharmacol Sin (2017) 38:233-40. doi:10.1038/aps.2016.107

36. Hoffknecht P, Tufman A, Wehler T, Pelzer T, Wiewrodt R, Schütz M, et al. Efficacy of the irreversible ErbB family blocker afatinib in epidermal growth factor receptor (EGFR) tyrosine kinase inhibitor (TKI)-pretreated nonsmall-cell lung cancer patients with brain metastases or leptomeningeal disease. J Thorac Oncol (2015) 10:156-63. doi:10.1097/JTO.0000000000000380

37. Schuler M, Wu Y-L, Hirsh V, O’Byrne K, Yamamoto N, Mok T, et al. Firstline afatinib versus chemotherapy in patients with non-small cell lung cancer and common epidermal growth factor receptor gene mutations and brain metastases. J Thorac Oncol (2016) 11:380-90. doi:10.1016/j.jtho.2015.11.014

38. Yang J-J, Zhou C, Huang Y, Feng J, Lu S, Song Y, et al. Icotinib versus wholebrain irradiation in patients with EGFR-mutant non-small-cell lung cancer and multiple brain metastases (BRAIN): a multicentre, phase 3, open-label, parallel, randomised controlled trial. Lancet Respir Med (2017) 5(9):707-16. doi:10.1016/S2213-2600(17)30262-X

39. Yun C-H, Mengwasser KE, Toms AV, Woo MS, Greulich H, Wong K-K, et al. The T790M mutation in EGFR kinase causes drug resistance by increasing the affinity for ATP. Proc Natl Acad Sci U S A (2008) 105:2070-5. doi:10.1073/ pnas. 0709662105

40. Sequist LV, Waltman BA, Dias-Santagata D, Digumarthy S, Turke AB, Fidias $P$, et al. Genotypic and histological evolution of lung cancers acquiring resistance to EGFR inhibitors. Sci Transl Med (2011) 3:75ra26. doi:10.1126/ scitranslmed.3002003

41. Yu HA, Arcila ME, Rekhtman N, Sima CS, Zakowski MF, Pao W, et al. Analysis of tumor specimens at the time of acquired resistance to EGFR-TKI therapy in 155 patients with EGFR-mutant lung cancers. Clin Cancer Res (2013) 19:2240-7. doi:10.1158/1078-0432.CCR-12-2246

42. Hata A, Katakami N, Yoshioka H, Takeshita J, Tanaka K, Nanjo S, et al. Rebiopsy of non-small cell lung cancer patients with acquired resistance to epidermal growth factor receptor-tyrosine kinase inhibitor: comparison between T790M mutation-positive and mutation-negative populations. Cancer (2013) 119:4325-32. doi:10.1002/cncr.28364

43. Hata A, Katakami N, Yoshioka H, Kaji R, Masago K, Fujita S, et al. Spatiotemporal T790M heterogeneity in individual patients with EGFRmutant non-small-cell lung cancer after acquired resistance to EGFR-TKI. J Thorac Oncol (2015) 10:1553-9. doi:10.1097/JTO.0000000000000647

44. Ballard P, Yates JWT, Yang Z, Kim D-W, Yang JC-H, Cantarini M, et al. Preclinical Comparison of osimertinib with other EGFR-TKIs in EGFRmutant NSCLC brain metastases models, and early evidence of clinical brain metastases activity. Clin Cancer Res (2016) 22:5130-40. doi:10.1158/10780432.CCR-16-0399

45. Yang JC-H, Ahn M-J, Kim D-W, Ramalingam SS, Sequist LV, Su W-C, et al. Osimertinib in pretreated T790M-positive advanced non-small-cell lung cancer: AURA study phase II extension component. J Clin Oncol (2017) 35(12):1288-96. doi:10.1200/JCO.2016.70.3223

46. Goss G, Tsai C-M, Shepherd FA, Bazhenova L, Lee JS, Chang G-C, et al. Osimertinib for pretreated EGFR Thr790Met-positive advanced non-small-cell lung cancer (AURA2): a multicentre, open-label, single-arm, phase 2 study. Lancet Oncol (2016) 17:1643-52. doi:10.1016/ S1470-2045(16)30508-3

47. Mok TS, Wu Y-L, Ahn M-J, Garassino MC, Kim HR, Ramalingam SS, et al. Osimertinib or platinum-pemetrexed in EGFR T790M-positive lung cancer. N Engl J Med (2017) 376(7):629-40. doi:10.1056/NEJMoa1612674

48. Yang J, Ramalingam SS, Jänne PA, Cantarini M, Mitsudomi T. LBA2_PR: osimertinib (AZD9291) in pre-treated pts with T790M-positive advanced NSCLC: updated phase 1 (P1) and pooled phase 2 (P2) results. J Thorac Oncol (2016) 11:S152-3. doi:10.1016/S1556-0864(16)30325-2

49. Goss G, Tsai C-M, Shepherd FA, Ahn M-J, Bazhenova L, Crinò L, et al. CNS response to osimertinib in patients with T790M-positive advanced NSCLC: pooled data from two phase II trials. Ann Oncol (2017). doi:10.1093/annonc/ mdx820

50. Goss G, Tsai C-M, Shepherd F, Ahn M-J, Bazhenova L, Crinò L, et al. MA16.11 CNS response to osimertinib in patients with T790M-positive advanced NSCLC: pooled data from two phase II trials. J Thorac Oncol (2017) 12:S440-1. doi:10.1016/j.jtho.2016.11.514

51. Mok T, Ahn M-J, Han J-Y, Kang JH, Katakami N, Kim H, et al. CNS response to osimertinib in patients (pts) with T790M-positive advanced NSCLC: data from a randomized phase III trial (AURA3). JClin Oncol (2017) 35:9005-9005. doi:10.1200/JCO.2017.35.15_suppl.9005

52. Zhang J, Yu J, Sun X, Meng X. Epidermal growth factor receptor tyrosine kinase inhibitors in the treatment of central nerve system metastases from non-small cell lung cancer. Cancer Lett (2014) 351:6-12. doi:10.1016/j. canlet.2014.04.019

53. Vansteenkiste J, Reungwetwattana T, Nakagawa K, Cho BC, Dols MAC, Cho EK, et al. LBA5CNS response to osimertinib vs standard of care (SoC) EGFR-TKI as first-line therapy in patients (pts) with EGFR-TKI sensitising mutation (EGFRm)-positive advanced non-small cell lung cancer (NSCLC): data from the FLAURA study. Ann Oncol (2017) 28:.007-.729. doi:10.1093/ annonc/mdx729.007

54. Jackman DM, Holmes AJ, Lindeman N, Wen PY, Kesari S, Borras AM, et al. Response and resistance in a non-small-cell lung cancer patient with an epidermal growth factor receptor mutation and leptomeningeal metastases treated with high-dose gefitinib. J Clin Oncol (2006) 24:4517-20. doi:10.1200/ JCO.2006.06.6126

55. Grommes C, Oxnard GR, Kris MG, Miller VA, Pao W, Holodny AI, et al. "Pulsatile" high-dose weekly erlotinib for CNS metastases from EGFR mutant non-small cell lung cancer. Neuro Oncol (2011) 13:1364-9. doi:10.1093/ neuonc/nor121

56. Kuiper JL, Smit EF. High-dose, pulsatile erlotinib in two NSCLC patients with leptomeningeal metastases - one with a remarkable thoracic response as well. Lung Cancer (2013) 80:102-5. doi:10.1016/j.lungcan.2012.12.024

57. Kuiper JL, Heideman DAM, Thunnissen E, van Wijk AW, Postmus PE, Smit EF. High-dose, weekly erlotinib is not an effective treatment in EGFR-mutated non-small cell lung cancer-patients with acquired extracranial progressive disease on standard dose erlotinib. Eur J Cancer (1990) 2014(50):1399-401. doi:10.1016/j.ejca.2014.02.005

58. Yu HA, Sima C, Feldman D, Liu LL, Vaitheesvaran B, Cross J, et al. Phase 1 study of twice weekly pulse dose and daily low-dose erlotinib as initial treatment for patients with EGFR-mutant lung cancers†. Ann Oncol (2017) 28:278-84. doi:10.1093/annonc/mdw556

59. Besse B, Le Moulec S, Mazieres J, Senellart H, Barlesi F, Chouaid C, et al. Bevacizumab in patients with nonsquamous non-small cell lung cancer and asymptomatic, untreated brain metastases (BRAIN): a nonrandomized, phase II study. Clin Cancer Res (2015) 21(8):1896-903. doi:10.1158/10780432.CCR-14-2082

60. Ilhan-Mutlu A, Osswald M, Liao Y, Gömmel M, Reck M, Miles D, et al. Bevacizumab prevents brain metastases formation in lung adenocarcinoma. Mol Cancer Ther (2016) 15:702-10. doi:10.1158/1535-7163.MCT-15-0582

61. Seto T, Kato T, Nishio M, Goto K, Atagi S, Hosomi Y, et al. Erlotinib alone or with bevacizumab as first-line therapy in patients with advanced non-squamous non-small-cell lung cancer harbouring EGFR mutations (JO25567): an openlabel, randomised, multicentre, phase 2 study. Lancet Oncol (2014) 15: 1236-44. doi:10.1016/S1470-2045(14)70381-X

62. Rosell R, Dafni U, Felip E, Curioni-Fontecedro A, Gautschi O, Peters S, et al. Erlotinib and bevacizumab in patients with advanced non-small-cell 
lung cancer and activating EGFR mutations (BELIEF): an international, multicentre, single-arm, phase 2 trial. Lancet Respir Med (2017) 5:435-44. doi:10.1016/S2213-2600(17)30129-7

63. Novello S, Barlesi F, Califano R, Cufer T, Ekman S, Levra MG, et al. Metastatic non-small-cell lung cancer: ESMO clinical practice guidelines for diagnosis, treatment and follow-up. Ann Oncol (2016) 27:v1-27. doi:10.1093/annonc/ mdw326

64. Soria J-C, Tan DSW, Chiari R, Wu Y-L, Paz-Ares L, Wolf J, et al. First-line ceritinib versus platinum-based chemotherapy in advanced ALK-rearranged non-small-cell lung cancer (ASCEND-4): a randomised, open-label, phase 3 study. Lancet (2017) 389:917-29. doi:10.1016/S0140-6736(17)30123-X

65. Peters S, Camidge DR, Shaw AT, Gadgeel S, Ahn JS, Kim D-W, et al. Alectinib versus crizotinib in untreated ALK-positive non-small-cell lung cancer. N Engl J Med (2017) 377(9):829-38. doi:10.1056/NEJMoa1704795

66. Shaw AT, Kim D-W, Nakagawa K, Seto T, Crino L, Ahn M-J, et al. Crizotinib versus chemotherapy in advanced ALK-positive lung cancer. $N$ Engl J Med (2013) 368:2385-94. doi:10.1056/NEJMoa1214886

67. Shaw AT, Kim D-W, Mehra R, Tan DSW, Felip E, Chow LQM, et al. Ceritinib in ALK-rearranged non-small-cell lung cancer. N Engl J Med (2014) 370:1189-97. doi:10.1056/NEJMoa1311107

68. Costa DB, Shaw AT, Ou S-HI, Solomon BJ, Riely GJ, Ahn M-J, et al. Clinical experience with crizotinib in patients with advanced ALK-rearranged nonsmall-cell lung cancer and brain metastases. J Clin Oncol (2015) 33:1881-8. doi:10.1200/JCO.2014.59.0539

69. Johung KL, Yeh N, Desai NB, Williams TM, Lautenschlaeger T, Arvold ND, et al. Extended survival and prognostic factors for patients with ALKrearranged non-small-cell lung cancer and brain metastasis. JClin Oncol (2016) 34:123-9. doi:10.1200/JCO.2015.62.0138

70. Solomon BJ, Cappuzzo F, Felip E, Blackhall FH, Costa DB, Kim D-W, et al. Intracranial efficacy of crizotinib versus chemotherapy in patients with advanced ALK-positive non-small-cell lung cancer: results from PROFILE 1014. J Clin Oncol (2016) 34:2858-65. doi:10.1200/JCO.2015.63.5888

71. Costa DB, Kobayashi S, Pandya SS, Yeo W-L, Shen Z, Tan W, et al. CSF concentration of the anaplastic lymphoma kinase inhibitor crizotinib. J Clin Oncol (2011) 29:e443-5. doi:10.1200/JCO.2010.34.1313

72. Gadgeel S, Peters S, Mok TSK, Shaw AT, Kim D-W, Ou S-HI, et al. 1298O_ PRAlectinib vs crizotinib in treatment-naïve ALK+ NSCLC: CNS efficacy results from the ALEX study. Ann Oncol (2017) 28:.057-.440. doi:10.1093/ annonc/mdx 440.057

73. Kim D-W, Mehra R, Tan DSW, Felip E, Chow LQM, Camidge DR, et al. Activity and safety of ceritinib in patients with ALK-rearranged non-small-cell lung cancer (ASCEND-1): updated results from the multicentre, open-label, phase 1 trial. Lancet Oncol (2016) 17:452-63. doi:10.1016/S1470-2045(15) 00614-2

74. Crinò L, Ahn M-J, De Marinis F, Groen HJ, Wakelee H, Hida T, et al. Multicenter phase II study of whole-body and intracranial activity with ceritinib in patients with ALK-rearranged non-small-cell lung cancer previously treated with chemotherapy and crizotinib: results from ASCEND-2. J Clin Oncol (2016) 34(24):2866-73. doi:10.1200/JCO.2015.65.5936

75. Felip E, Orlov S, Park K, Yu C-J, Tsai C-M, Nishio M, et al. Phase 2 study of ceritinib in ALKi-naïve patients (pts) with ALK-rearranged (ALK+) nonsmall cell lung cancer (NSCLC): whole body responses in the overall pt group and in pts with baseline brain metastases (BM). Ann Oncol (2016) 27:1208O. doi:10.1093/annonc/mdw383.03

76. Shaw AT, Kim TM, Crinò L, Gridelli C, Kiura K, Liu G, et al. Ceritinib versus chemotherapy in patients with ALK-rearranged non-small-cell lung cancer previously given chemotherapy and crizotinib (ASCEND-5): a randomised, controlled, open-label, phase 3 trial. Lancet Oncol (2017) 18:874-86. doi:10.1016/S1470-2045(17)30339-X

77. Cho BC, Kim D-W, Bearz A, Laurie SA, McKeage M, Borra G, et al. ASCEND-8: a randomized phase 1 study of ceritinib, $450 \mathrm{mg}$ or $600 \mathrm{mg}$, taken with a low-fat meal versus $750 \mathrm{mg}$ in fasted state in patients with anaplastic lymphoma kinase (ALK)-rearranged metastatic non-small cell lung cancer (NSCLC). J Thorac Oncol 12:1357-67. doi:10.1016/j.jtho.2017.07.005

78. Cho BC, Obermannová R, Bearz A, Kim D, Orlov S, Borra G, et al. OA 05.07 efficacy and updated safety of ceritinib $(450 \mathrm{Mg}$ or $600 \mathrm{Mg}$ ) with low-fat meal vs $750 \mathrm{Mg}$ fasted in ALK+ metastatic NSCLC. J Thorac Oncol 12:S1757. doi:10.1016/j.jtho.2017.09.352
79. Gainor JF, Dardaei L, Yoda S, Friboulet L, Leshchiner I, Katayama R, et al. Molecular mechanisms of resistance to first- and second-generation ALK inhibitors in ALK-rearranged lung cancer. Cancer Discov (2016) 6:1118-33. doi:10.1158/2159-8290.CD-16-0596

80. Gainor JF, Sherman CA, Willoughby K, Logan J, Kennedy E, Brastianos PK, et al. Alectinib salvages CNS relapses in ALK-positive lung cancer patients previously treated with crizotinib and ceritinib. J Thorac Oncol (2015) 10:232-6. doi:10.1097/JTO.0000000000000455

81. Gadgeel SM, Gandhi L, Riely GJ, Chiappori AA, West HL, Azada MC, et al. Safety and activity of alectinib against systemic disease and brain metastases in patients with crizotinib-resistant ALK-rearranged non-small-cell lung cancer (AF-002JG): results from the dose-finding portion of a phase $1 / 2$ study. Lancet Oncol (2014) 15:1119-28. doi:10.1016/S1470-2045(14)70362-6

82. Shaw AT, Gandhi L, Gadgeel S, Riely GJ, Cetnar J, West H, et al. Alectinib in ALK-positive, crizotinib-resistant, non-small-cell lung cancer: a single-group, multicentre, phase 2 trial. Lancet Oncol (2016) 17:234-42. doi:10.1016/S1470-2045(15)00488-X

83. Ou S-HI, Ahn JS, De Petris L, Govindan R, Yang JC-H, Hughes B, et al. Alectinib in crizotinib-refractory ALK-rearranged non-small-cell lung cancer: a phase II global study. J Clin Oncol (2016) 34:661-8. doi:10.1200/ JCO.2015.63.9443

84. Yang JC-H, Ou S-I, De Petris L, Gadgeel S, Gandhi L, Kim D-W, et al. Pooled systemic efficacy and safety data from the pivotal phase II studies (NP28673 and NP28761) of alectinib in ALK-positive non-small-cell lung cancer. $J$ Thorac Oncol (2017) 12(10):1552-60. doi:10.1016/j.jtho.2017.06.070

85. Gadgeel SM, Shaw AT, Govindan R, Gandhi L, Socinski MA, Camidge DR, et al. Pooled analysis of CNS response to alectinib in two studies of pretreated patients with ALK-positive non-small-cell lung cancer. JClin Oncol (2016) 34:4079-85. doi:10.1200/JCO.2016.68.4639

86. Novello S, Mazieres J, Oh I-J, de Castro J, Migliorino MR, Helland A, et al. 1299O_PRPrimary results from the phase III ALUR study of alectinib versus chemotherapy in previously treated ALK+ non-small-cell lung cancer (NSCLC). Ann Oncol (2017) 28:.058-.440. doi:10.1093/annonc/mdx440.058

87. de Castro J, Novello S, Mazieres J, Oh I-J, Migliorino MR, Helland A, et al. 1346PCNS efficacy results from the phase III ALUR study of alectinib vs chemotherapy in previously treated ALK+ NSCLC. Ann Oncol (2017) 28:.048-.380. doi:10.1093/annonc/mdx380.048

88. Hida T, Nokihara H, Kondo M, Kim YH, Azuma K, Seto T, et al. Alectinib versus crizotinib in patients with ALK-positive non-small-cell lung cancer (J-ALEX): an open-label, randomised phase 3 trial. Lancet (2017) 390:29-39. doi:10.1016/S0140-6736(17)30565-2

89. Zou HY, Friboulet L, Kodack DP, Engstrom LD, Li Q, West M, et al. PF06463922, an ALK/ROS1 inhibitor, overcomes resistance to first and second generation ALK inhibitors in preclinical models. Cancer Cell (2015) 28:70-81. doi:10.1016/j.ccell.2015.05.010

90. Shaw AT, Felip E, Bauer TM, Besse B, Navarro A, Postel-Vinay S, et al. Lorlatinib in non-small-cell lung cancer with ALK or ROS1 rearrangement: an international, multicentre, open-label, single-arm first-in-man phase 1 trial. Lancet Oncol (2017) 18(12):1590-9. doi:10.1016/S1470-2045(17)30680-0

91. Solomon B, Shaw A, Ou S, Besse B, Felip E, Bauer T, et al. OA 05.06 phase 2 study of lorlatinib in patients with advanced ALK+/ROS1+ non-small-cell lung cancer. J Thorac Oncol 12:S1756. doi:10.1016/j.jtho.2017.09.351

92. Zhang S, Anjum R, Squillace R, Nadworny S, Zhou T, Keats J, et al. The potent ALK inhibitor brigatinib (AP26113) overcomes mechanisms of resistance to first- and second-generation ALK inhibitors in preclinical models. Clin Cancer Res (2016) 22:5527-38. doi:10.1158/1078-0432.CCR-16-0569

93. Gettinger SN, Bazhenova LA, Langer CJ, Salgia R, Gold KA, Rosell R, et al. Activity and safety of brigatinib in ALK-rearranged non-small-cell lung cancer and other malignancies: a single-arm, open-label, phase 1/2 trial. Lancet Oncol (2016) 17:1683-96. doi:10.1016/S1470-2045(16)30392-8

94. Kim D-W, Tiseo M, Ahn M-J, Reckamp KL, Hansen KH, Kim S-W, et al. Brigatinib in patients with crizotinib-refractory anaplastic lymphoma kinase-positive non-small-cell lung cancer: a randomized, multicenter phase II trial. J Clin Oncol (2017) 35(22):2490-8. doi:10.1200/JCO.2016.71.5904

95. Ahn M, Camidge DR, Tiseo M, Reckamp K, Hansen K, Kim S, et al. OA 05.05 brigatinib in crizotinib-refractory ALK+ NSCLC: updated efficacy and safety results from ALTA, a randomized phase 2 trial. J Thorac Oncol (2017) 12:S1755-6. doi:10.1016/j.jtho.2017.09.350 
96. Horn L, Wakelee H, Reckamp K, Blumenschein G, Infante J, Carter C, et al. P3.02a-001 response and plasma genotyping from phase I/II trial of ensartinib (X-396) in patients (Pts) with ALK+ NSCLC. J Thorac Oncol (2017) 12:S1159. doi:10.1016/j.jtho.2016.11.1631

97. Wakelee H, Sanborn R, Nieva J, Waqar S, Brzezniak C, Bauman J, et al. MA 07.02 response to ensartinib in TKI naïve ALK+ NSCLC patients. J Thorac Oncol 12:S1826. doi:10.1016/j.jtho.2017.09.504

98. Reckamp KL, Wakelee HA, Patel S, Blumenschein G, Neal JW, Gitlitz B, et al. 88OCNS activity of ensartinib in ALK+ non-small cell lung cancer (NSCLC) patients (pts). Ann Oncol (2017) 28:mdx091.008. doi:10.1093/ annonc/mdx091.008

99. Gainor JF, Tseng D, Yoda S, Dagogo-Jack I, Friboulet L, Lin JJ, et al. Patterns of metastatic spread and mechanisms of resistance to crizotinib in ROS1positive non-small-cell lung cancer. JCO Precis Oncol (2017) 1:1-13. doi:10.1200/PO.17.00063

100. Preusser M, Streubel B, Birner P. ROS1 translocations and amplifications in lung cancer brain metastases. J Neurooncol (2014) 118:425-6. doi:10.1007/ s11060-014-1446-x

101. Shaw AT, Ou S-HI, Bang Y-J, Camidge DR, Solomon BJ, Salgia R, et al. Crizotinib in ROS1-rearranged non-small-cell lung cancer. N Engl J Med (2014) 371:1963-71. doi:10.1056/NEJMoa1406766

102. Lim SM, Kim HR, Lee J-S, Lee KH, Lee Y-G, Min YJ, et al. Open-label, multicenter, phase II study of ceritinib in patients with non-small-cell lung cancer harboring ROS1 rearrangement. J Clin Oncol (2017) 35(23):2613-8. doi:10.1200/JCO.2016.71.3701

103. Ahn M, Cho BC, Siena S, Drilon A, De Braud F, Krebs M, et al. OA 14.06 entrectinib in patients with locally advanced or metastatic ROS1 fusion-positive non-small cell lung cancer (NSCLC). J Thorac Oncol 12:S1783. doi:10.1016/ j.jtho.2017.09.411

104. Drilon A, Siena S, Ou S-HI, Patel M, Ahn MJ, Lee J, et al. Safety and antitumor activity of the multitargeted pan-TRK, ROS1, and ALK inhibitor entrectinib: combined results from two phase I trials (ALKA-372-001 and STARTRK-1). Cancer Discov (2017) 7:400-9. doi:10.1158/2159-8290.CD-16-1237

105. Gautschi O, Milia J, Filleron T, Wolf J, Carbone DP, Owen D, et al. Targeting RET in patients with RET-rearranged lung cancers: results from the global, multicenter ret registry. JClin Oncol (2017) 35:1403-10. doi:10.1200/ JCO.2016.70.9352

106. Ferrara R, Auger N, Auclin E, Besse B. Clinical and translational implications of RET rearrangements in non-small cell lung cancer. J Thorac Oncol (2018) 13(1):27-45. doi:10.1016/j.jtho.2017.10.021

107. Drilon A, Bergagnini I, Delasos L, Sabari J, Woo KM, Plodkowski A, et al. Clinical outcomes with pemetrexed-based systemic therapies in RETrearranged lung cancers. Ann Oncol (2016) 27:1286-91. doi:10.1093/annonc/ mdw163

108. Drilon A, Rekhtman N, Arcila M, Wang L, Ni A, Albano M, et al. Cabozantinib in patients with advanced RET-rearranged non-small-cell lung cancer: an open-label, single-centre, phase 2, single-arm trial. Lancet Oncol (2016) 17:1653-60. doi:10.1016/S1470-2045(16)30562-9

109. Yoh K, Seto T, Satouchi M, Nishio M, Yamamoto N, Murakami H, et al. Vandetanib in patients with previously treated RET-rearranged advanced non-small-cell lung cancer (LURET): an open-label, multicentre phase 2 trial. Lancet Respir Med (2017) 5:42-50. doi:10.1016/S2213-2600(16) 30322-8

110. Lee S-H, Lee J-K, Ahn M-J, Kim D-W, Sun J-M, Keam B, et al. Vandetanib in pretreated patients with advanced non-small cell lung cancer-harboring RET rearrangement: a phase II clinical trial. Ann Oncol (2017) 28:292-7. doi:10.1093/annonc/mdw559

111. Drilon AE, Filleron T, Bergagnini I, Milia J, Hatzoglou V, Velcheti V, et al. Baseline frequency of brain metastases and outcomes with multikinase inhibitor therapy in patients with RET-rearranged lung cancers. J Clin Oncol (2017) 35:9069-9069. doi:10.1200/JCO.2017.35.15_suppl.9069

112. Lin JJ, Kennedy E, Sequist LV, Brastianos PK, Goodwin KE, Stevens S, et al. Clinical activity of alectinib in advanced RET-rearranged non-small cell lung cancer. J Thorac Oncol (2016) 11:2027-32. doi:10.1016/j.jtho.2016.08.126

113. Velcheti V, Bauer T, Subbiah V, Cabanillas M, Lakhani N, Wirth L, et al. OA 12.07 LOXO-292, a potent, highly selective RET inhibitor, in MKI-resistant RET fusion-positive lung cancer patients with and without brain metastases. J Thorac Oncol (2017) 12:S1778. doi:10.1016/j.jtho.2017.09.399
114. Subbiah V, Berry J, Roxas M, Guha-Thakurta N, Subbiah IM, Ali SM, et al. Systemic and CNS activity of the RET inhibitor vandetanib combined with the mTOR inhibitor everolimus in KIF5B-RET re-arranged non-small cell lung cancer with brain metastases. Lung Cancer (2015) 89:76-9. doi:10.1016/j. lungcan.2015.04.004

115. Cascone T, Hess KR, Piha-Paul SA, Hong DS, Subbiah IM, Bhatt T, et al. Safety, toxicity and activity of multi-kinase inhibitor vandetanib in combination with everolimus in advanced solid tumors. J Clin Oncol (2016) 34:9073-9073. doi:10.1200/JCO.2016.34.15_suppl.9073

116. Plenker D, Riedel M, Brägelmann J, Dammert MA, Chauhan R, Knowles PP, et al. Drugging the catalytically inactive state of RET kinase in RET-rearranged tumors. Sci Transl Med (2017) 9:eaah6144. doi:10.1126/scitranslmed.aah6144

117. Planchard D, Besse B, Kim TM, Quoix EA, Souquet PJ, Mazieres J, et al. Updated survival of patients (pts) with previously treated BRAF V600Emutant advanced non-small cell lung cancer (NSCLC) who received dabrafenib (D) or D + trametinib (T) in the phase II BRF113928 study. J Clin Oncol (2017) 35:9075-9075. doi:10.1200/JCO.2017.35.15_suppl.9075

118. Planchard D, Smit EF, Groen HJM, Mazieres J, Besse B, Helland $\AA$, et al. Dabrafenib plus trametinib in patients with previously untreated BRAF(V600E)-mutant metastatic non-small-cell lung cancer: an open-label, phase 2 trial. Lancet Oncol (2017) 18:1307-16. doi:10.1016/S1470-2045 (17)30679-4

119. Davies MA, Saiag P, Robert C, Grob J-J, Flaherty KT, Arance A, et al. Dabrafenib plus trametinib in patients with BRAF(V600)-mutant melanoma brain metastases (COMBI-MB): a multicentre, multicohort, open-label, phase 2 trial. Lancet Oncol (2017) 18:863-73. doi:10.1016/S1470-2045(17) 30429-1

120. Farago AF, Le LP, Zheng Z, Muzikansky A, Drilon A, Patel M, et al. Durable clinical response to entrectinib in NTRK1-rearranged non-small cell lung cancer. J Thorac Oncol (2015) 10:1670-4. doi:10.1097/01.JTO. 0000473485.38553.f0

121. Hyman DM, Laetsch TW, Kummar S, DuBois SG, Farago AF, Pappo AS, et al. The efficacy of larotrectinib (LOXO-101), a selective tropomyosin receptor kinase (TRK) inhibitor, in adult and pediatric TRK fusion cancers. J Clin Oncol (2017) 35:LBA2501-2501. doi:10.1200/JCO.2017.35.18_suppl. LBA2501

122. Soffietti R, Abacioglu U, Baumert B, Combs SE, Kinhult S, Kros JM, et al. Diagnosis and treatment of brain metastases from solid tumors: guidelines from the European association of neuro-oncology (EANO). Neuro Oncol (2017) 19:162-74. doi:10.1093/neuonc/now241

123. Soon YY, Leong CN, Koh WY, Tham IWK. EGFR tyrosine kinase inhibitors versus cranial radiation therapy for EGFR mutant non-small cell lung cancer with brain metastases: a systematic review and meta-analysis. Radiother Oncol (2015) 114:167-72. doi:10.1016/j.radonc.2014.12.011

124. Magnuson WJ, Lester-Coll NH, Wu AJ, Yang TJ, Lockney NA, Gerber NK, et al. Management of brain metastases in tyrosine kinase inhibitor-naïve epidermal growth factor receptor-mutant non-small-cell lung cancer: a retrospective multi-institutional analysis. JClin Oncol (2017) 35:1070-7. doi:10.1200/JCO.2016.69.7144

125. Fan Y, Xu Y, Gong L, Fang L, Lu H, Qin J, et al. Effects of icotinib with and without radiation therapy on patients with EGFR mutant non-small cell lung cancer and brain metastases. Sci Rep (2017) 7:45193. doi:10.1038/srep45193

126. Jiang T, Min W, Li Y, Yue Z, Wu C, Zhou C. Radiotherapy plus EGFR TKIs in non-small cell lung cancer patients with brain metastases: an update meta-analysis. Cancer Med (2016) 5:1055-65. doi:10.1002/cam4.673

127. Welsh JW, Komaki R, Amini A, Munsell MF, Unger W, Allen PK, et al. Phase II trial of erlotinib plus concurrent whole-brain radiation therapy for patients with brain metastases from non-small-cell lung cancer. J Clin Oncol (2013) 31:895-902. doi:10.1200/JCO.2011.40.1174

128. Zhu Q, Sun Y, Cui Y, Ye K, Yang C, Yang D, et al. Clinical outcome of tyrosine kinase inhibitors alone or combined with radiotherapy for brain metastases from epidermal growth factor receptor (EGFR) mutant non small cell lung cancer (NSCLC). Oncotarget (2017) 8:13304-11. doi:10.18632/ oncotarget. 14515

129. Jiang T, Su C, Li X, Zhao C, Zhou F, Ren S, et al. EGFR TKIs plus WBRT demonstrated no survival benefit other than that of TKIs alone in patients with NSCLC and EGFR mutation and brain metastases. J Thorac Oncol (2016) 11:1718-28. doi:10.1016/j.jtho.2016.05.013 
130. Hendriks LEL, Schoenmaekers J, Zindler JD, Eekers DBP, Hoeben A, De Ruysscher DKM, et al. Safety of cranial radiotherapy concurrent with tyrosine kinase inhibitors in non-small cell lung cancer patients: a systematic review. Cancer Treat Rev (2015) 41:634-45. doi:10.1016/j.ctrv.2015. 05.005

131. Tallet AV, Dhermain F, Le Rhun E, Noël G, Kirova YM. Combined irradiation and targeted therapy or immune checkpoint blockade in brain metastases: toxicities and efficacy. Ann Oncol (2017) 28:2962-76. doi:10.1093/annonc/ $\operatorname{mdx} 408$

132. Kim YH, Ozasa H, Nagai H, Sakamori Y, Yoshida H, Yagi Y, et al. Highdose crizotinib for brain metastases refractory to standard-dose crizotinib. J Thorac Oncol (2013) 8:e85-6. doi:10.1097/JTO.0b013e31829cebbb

133. Gandhi L, Drappatz J, Ramaiya NH, Otterson GA. High-dose pemetrexed in combination with high-dose crizotinib for the treatment of refractory CNS metastases in ALK-rearranged non-small-cell lung cancer. J Thorac Oncol (2013) 8:e3-5. doi:10.1097/JTO.0b013e3182762d20

134. Tang SC, Nguyen LN, Sparidans RW, Wagenaar E, Beijnen JH, Schinkel AH. Increased oral availability and brain accumulation of the ALK inhibitor crizotinib by coadministration of the P-glycoprotein (ABCB1) and breast cancer resistance protein (ABCG2) inhibitor elacridar. Int J Cancer (2014) 134:1484-94. doi:10.1002/ijc.28475

135. Ou S-HI, Jänne PA, Bartlett CH, Tang Y, Kim D-W, Otterson GA, et al. Clinical benefit of continuing ALK inhibition with crizotinib beyond initial disease progression in patients with advanced ALK-positive NSCLC. Ann Oncol (2014) 25:415-22. doi:10.1093/annonc/mdt572

136. Takeda M, Okamoto I, Nakagawa K. Clinical impact of continued crizotinib administration after isolated central nervous system progression in patients with lung cancer positive for ALK rearrangement. J Thorac Oncol (2013) 8:654-7. doi:10.1097/JTO.0b013e31828c28e7

137. Weickhardt AJ, Scheier B, Burke JM, Gan G, Lu X, Bunn PA, et al. Local ablative therapy of oligoprogressive disease prolongs disease control by tyrosine kinase inhibitors in oncogene-addicted non-small-cell lung cancer. $J$ Thorac Oncol (2012) 7:1807-14. doi:10.1097/JTO.0b013e3182745948

138. Mak KS, Gainor JF, Niemierko A, Oh KS, Willers H, Choi NC, et al. Significance of targeted therapy and genetic alterations in EGFR, ALK, or KRAS on survival in patients with non-small cell lung cancer treated with radiotherapy for brain metastases. Neuro Oncol (2015) 17:296-302. doi:10.1093/neuonc/noul46

139. Sullivan I, Planchard D. Treatment modalities for advanced ALK-rearranged non-small-cell lung cancer. Future Oncol (2016) 12:945-61. doi:10.2217/ fon. 16.15

140. Remon J, Menis J, Hasan B, Peric A, De Maio E, Novello S, et al. The APPLE trial: feasibility and activity of AZD9291 (osimertinib) treatment on positive plasma T790M in EGFR-mutant NSCLC patients. EORTC 1613. Clin Lung Cancer (2017) 18:583-8. doi:10.1016/j.cllc.2017.02.005

141. Nishio M, Kiura K, Seto T, Nakagawa K, Maemondo M, Inoue A, et al. OA 05.08 final result of phase I/II study (AF-001JP) of alectinib, a selective CNS-active ALK inhibitor, in ALK+ NSCLC patients (Pts). J Thorac Oncol 12:S1757. doi:10.1016/j.jtho.2017.09.353

142. Mok TSK, Kim D-W, Wu Y-L, Nakagawa K, Mekhail T, Felip E, et al. LBA50Overall survival (OS) for first-line crizotinib versus chemotherapy in ALK+ lung cancer: updated results from PROFILE 1014. Ann Oncol (2017) 28:.053-.440. doi:10.1093/annonc/mdx440.053

143. Ito K, Hataji O, Kobayashi H, Fujiwara A, Yoshida M, D’Alessandro-Gabazza CN, et al. Sequential therapy with crizotinib and alectinib in ALK-rearranged non-small cell lung cancer-a multicenter retrospective study. J Thorac Oncol (2017) 12:390-6. doi:10.1016/j.jtho.2016.07.022

144. Gainor JF, Tan DSW, De Pas T, Solomon BJ, Ahmad A, Lazzari C, et al. Progression-free and overall survival in ALK-positive NSCLC patients treated with sequential crizotinib and ceritinib. Clin Cancer Res (2015) 21:2745-52. doi:10.1158/1078-0432.CCR-14-3009

145. Watanabe S, Hayashi H, Okamoto K, Fujiwara K, Hasegawa Y, Kaneda H, et al. Progression-free and overall survival of patients with ALK rearrangement-positive non-small cell lung cancer treated sequentially with crizotinib and alectinib. Clin Lung Cancer (2016) 17:528-34. doi:10.1016/j. cllc.2016.05.001

146. Duruisseaux M, Besse B, Cadranel J, Pérol M, Mennecier B, Bigay-Game L, et al. Overall survival with crizotinib and next-generation ALK inhibitors in ALK-positive non-small-cell lung cancer (IFCT-1302 CLINALK): a French nationwide cohort retrospective study. Oncotarget (2017) 8:21903-17. doi:10.18632/oncotarget.15746

147. Pailler E, Oulhen M, Borget I, Remon J, Ross K, Auger N, et al. Circulating tumor cells with aberrant ALK copy number predict progression-free survival during crizotinib treatment in ALK-rearranged non-small cell lung cancer patients. Cancer Res (2017) 77:2222-30. doi:10.1158/0008-5472.CAN-16-3072

Conflict of Interest Statement: The authors declare that the research was conducted in the absence of any commercial or financial relationships that could be construed as a potential conflict of interest.

Copyright (C) 2018 Remon and Besse. This is an open-access article distributed under the terms of the Creative Commons Attribution License (CC BY). The use, distribution or reproduction in other forums is permitted, provided the original author(s) and the copyright owner are credited and that the original publication in this journal is cited, in accordance with accepted academic practice. No use, distribution or reproduction is permitted which does not comply with these terms. 